\title{
A posição dos advérbios focalizadores na hierarquia universal
}

\section{The position of focusing adverbs in the universal hierarchy}

Aquiles Tescari Neto

UNICAMP

tescari@iel.unicamp.br

Resumo: Apesar de sua abrangência empírica e conceitual, a hierarquia universal de Cinque (1999) não contempla posições para AdvPs focalizadores de diferentes classes (semânticas). A literatura linguística geral (QUIRK et al., 1976; RICCA, 1999; ADORNO, 2000; CESARE, 2010; entre outros) reconhece pelo menos as seguintes classes de advérbios focalizadores: (a) de exclusão (somente), (b) aditivos não escalares (também), (c) aditivos escalares (até), (d) de inclusão (inclusive) e (e) particularizadores (principalmente). Diante desse quadro, a pergunta que se faz, assumindo-se a vertente cartográfica da Teoria de Princípios e Parâmetros, é: "Qual/quais a(s) posição(posições) que essas diferentes classes (semânticas) de advérbios focalizadores ocupariam em termos de hierarquias?". O trabalho procura responder a essa pergunta assumindo, com o Programa Cartográfico, que cada uma dessas diferentes classes teria uma posição distinta de Soldagem (merge), seguindo o princípio do "One Feature, One Head" (um traço, um núcleo) (KAYNE, 2005). Com base em testes de transitividade envolvendo dois advérbios focalizadores de cada vez, aplicados a dados do português brasileiro e do espanhol, este trabalho propõe uma hierarquia para as cinco classes de AdvPs focalizadores citados, estabelecendo também a posição de cada focalizador específico em relação aos outros advérbios da hierarquia de Cinque. 
Palavras-chave: advérbios focalizadores; advérbios altos; hierarquia universal; cartografia; sintaxe gerativa.

Abstract: In spite of its empirical and conceptual scope, Cinque's (1999) universal hierarchy does not include dedicated positions for focusing AdvPs of different (semantic) classes. The general Linguistics literature (QUIRK et al., 1976; RICCA, 1999; ADORNO, 2000; CESARE, 2010; among others) recognizes at least the following classes of focusing adverbs: (a) exclusive adverbs (only) (b) non-scalar additives (also), (c) scalar additives (even), (d) inclusion adverbs (including) and (e) particularizers (mainly). Given this acknowledgment, one should ask, assuming the cartographic point of view regarding the Theory of Principles and Parameters, which position(s) these different (semantic) classes of focusing adverbs would occupy in terms of functional hierarchies. The study attempts to answer this question by assuming, with the Cartography Program, that each different class of focusing adverb would have a distinct position of Merge, in accordance with the "One Feature, One Head" principle (KAYNE, 2005). Based on transitivity tests involving two focusing adverbs in the same sentence in two possible orders, applied to Brazilian Portuguese and American Spanish data, this paper proposes a hierarchy for the five classes of the mentioned focusing AdvPs, also establishing the position of each focusing adverb regarding the other adverbs in Cinque's hierarchy.

Keywords: focusing adverbs; high adverbs; universal hierarchy; cartography; generative syntax.

Recebido em 06 de julho de 2015. Aprovado em 04 de dezembro de 2015. 


\section{Considerações iniciais}

Embora a focalização por advérbios tenha sido objeto de estudo em Sintaxe Gerativa (pelo menos) desde Chomsky (1971) (cf. BAYER, 1990, 1996; LONGOBARDI, 1992; ZUBIZARRETA, 1998, KAYNE 1998; LIMA, 2006; KRIFKA, 2007; AMBAR, 2008; SHU, 2011; MUNARO, 2011), nenhuma das propostas anteriormente citadas se propôs a estabelecer a posição que advérbios associados ao foco - tradicionalmente denominados de "advérbios focalizadores", que formam um grupo com cerca de cinco classes semanticamente distintas (p. ex., só e até) - ocupariam numa hierarquia de advérbios (como a de Cinque, 1999, por exemplo). Com os avanços recentes do "Programa Cartográfico", essa investigação torna-se necessária por duas razões. Primeiro, em virtude do objetivo geral desse programa, que busca fornecer um mapeamento o mais detalhado possível da estrutura da oração e dos seus sintagmas principais (CINQUE, 2002, 2006; CINQUE; RIZZI, 2010; BENINCÀ; MUNARO, 2011). Segundo, em função da premissa segundo a qual cada categoria sintática teria uma posição rígida e fixa nas hierarquias, conforme prevê o princípio do "One Feature, One Head" ("um traço, um núcleo"), de Kayne (2005), que é o ponto de partida de toda pesquisa em Sintaxe Cartográfica (CINQUE; RIZZI, 2010). Apesar da sua abrangência empírica, o trabalho de Cinque (1999) não contemplou os modificadores ditos focalizadores do tipo de só, somente (e seus correspondentes nas diferentes línguas), até, até mesmo, e outras subclasses desses advérbios que se associam ao foco.

Assumindo que o Programa Cartográfico esteja no caminho correto e que a assunção do princípio do "One Feature, One Head" (KAYNE, 2005) se revela como opção teórico-conceitual adequada, espera-se que não só os AdvPs estudados por Cinque (1999) - que perfazem cerca de trinta classes semânticas - se ordenem rigidamente, i.e., ocupem uma posição fixa na hierarquia universal da oração, como também os AdvPs conhecidos na literatura como "focalizadores", que, de acordo com as descrições feitas em Quirk et al. (1976), Ricca (1999), Shu (2011), Ferrari, Giammatteo e Albano (2011), dentre outros, encontramse distribuídos nas seguintes classes: (i) os restritivos de exclusão (só, exclusivamente, meramente etc.); (ii) os restritivos particularizadores (especialmente, principalmente, particularmente etc.); (iii) os aditivos escalares (até, até mesmo, mesmo); (iv) os aditivos não escalares (também); e (v) os inclusivos (inclusive). Essa é a nossa hipótese inicial. 
Baseando-se amplamente em Tescari Neto (2015a) e avançando a sua proposta, este trabalho traz contribuições ao Programa Cartográfico por procurar mostrar, com base na distribuição sintática das cinco subclasses de AdvPs focalizadores, mencionadas no parágrafo anterior, que tais AdvPs não só se ordenam de maneira rígida e fixa (entre si) como também em relação aos outros AdvPs da hierarquia de Cinque. Para isso, organiza-se da seguinte maneira: na primeira seção, faz-se uma descrição das subclasses semânticas de AdvPs focalizadores, com apoio nos autores mencionados no parágrafo anterior. Na segunda seção, apresenta-se a metodologia de Cinque para derivar a sua hierarquia universal de advérbios via "testes de transitividade". Tais testes são empregados a dados do português brasileiro (PB) e do espanhol (de Lima e de Buenos Aires), envolvendo os advérbios focalizadores que nos interessam aqui (terceira seção), visando a chegar não só a uma hierarquia de advérbios focalizadores como também a uma hierarquia geral de advérbios (focalizadores e não focalizadores) (quarta seção). Na última seção, são retomadas as seções e apresentados os problemas em aberto.

\section{Os advérbios "focalizadores"}

Advérbios focalizadores ${ }^{1}$ explicitam que "[...] o que está sendo comunicado se restringe à parte focalizada, e nesse caso eles são chamados "restritivos", ou que a parte focalizada é uma adição, e neste caso são chamados 'aditivos' [...]" (QUIRK et al., 1976, p. 431). Em Shu (2011), os advérbios focalizadores são denominados de "advérbios associados ao foco" pelo fato de a atribuição de foco ao constituinte focalizado não depender do advérbio, mas de um movimento do

\footnotetext{
${ }^{1}$ Embora a tradição gramatical - pelo menos a portuguesa - não dê um tratamento uniforme às cinco classes de "advérbios" focalizadores aqui mencionados, o artigo segue a literatura resenhada nesta seção, que reconhece tais palavras como advérbios. Do ponto de vista da sintaxe, o que motiva o reconhecimento dos "focalizadores" como advérbios é o fato de, à semelhança dos outros (cerca de) quarenta advérbios da hierarquia de Cinque (1999), poderem modificar o verbo e outros constituintes sentenciais. Agrega-se a isso o fato de grande parte deles apresentarem o sufixo-mente, típico de advérbios em português e espanhol, as duas línguas aqui consideradas para a investigação. Para uma leitura das propriedades sintáticas dos advérbios focalizadores, ver Tescari Neto (2015b).
} 
constituinte a ser focalizado ao especificador da projeção de foco numa das periferias (alta ou baixa).

Cinco são as classes de advérbios focalizadores reconhecidas pela literatura (QUIRK et al., 1976; RICCA, 1999; ADORNO, 2000; SHU, 2011; FERRARI; GIAMMATEO; ALBANO, 2011):

(i) os restritivos de exclusão: só, exclusivamente, meramente etc.;

(ii) os restritivos particularizadores: especialmente, principalmente, particularmente etc.;

(iii) os aditivos escalares: até, até mesmo, mesmo etc.;

(iv) os aditivos não escalares: também;

(v) os inclusivos: inclusive.

Os advérbios de exclusão (só, exatamente, precisamente, meramente, puramente, simplesmente, somente etc.) restringem a aplicação do conteúdo comunicado exclusivamente à parte focalizada:

(1) O Pedro come só arroz.

Em (1), o advérbio restringe o universo de alimentos que o Pedro come a um só: o NP/DP arroz. Conforme veremos mais adiante, o advérbio só ocupa uma posição entre os advérbios altos, mais precisamente a posição mais baixa entre todos os advérbios altos.

Os AdvPs particularizadores, por sua vez, restringem a aplicação do conteúdo comunicado particularmente à parte focalizada (ver (2). Em português, representam a classe: particularmente, especialmente, principalmente, notavelmente, primariamente, especificamente, dentre outros.

(2) O João gosta principalmente de doces.

Repare que, em (2), o advérbio assinala que, considerando o universo dos alimentos de que o João gosta, ele prefere os doces. Conforme será visto adiante, os particularizadores são os segundos mais altos na hierarquia de advérbios focalizadores.

Os advérbios aditivos tornam explícito que o conteúdo comunicado é uma adição. Subdividem-se em duas classes, cada uma delas correspondendo, conforme veremos adiante, a uma posição específica 
(de Soldagem "Merge"2) no Middlefield ${ }^{3}$. No caso dos aditivos escalares (até), esses itens induzem uma ordenação no conjunto de alternativas (Ricca, 1999). Comparando (3) com (4), exemplos de Ricca (1999),

(3) John also reads SHAKESPEARE ${ }^{4}$. João também lê Shakeaspeare.

(4) John even reads SHAKESPEARE. João até lê Shakespeare.

percebemos que apenas (4), que envolve um aditivo escalar, even ("até"), sugere que Shakespeare seja uma leitura mais difícil do que outras alternativas. Não se pode fazer a mesma inferência sobre (3), que envolve o advérbio also ("também"), um aditivo não escalar. A mesma observação vale para o português: (3'), o correspondente de (3), não pressupõe a existência de leituras difíceis, inferência possível se se trata de um aditivo escalar como até, de (4').

(3') João lê SHAKESPEARE também.

(4') João lê até SHAKESPEARE.

Conforme se verá adiante, o aditivo não escalar também precede o aditivo escalar até que, por sua vez, precede o focalizador de exclusão só.

Uma quinta classe de focalizadores congrega advérbios como inclusive que, conforme veremos, ocupam a posição mais alta dentre as cinco classes de AdvPs associados ao foco investigadas neste trabalho. (5) ilustra o uso de um focalizador de inclusão.

\footnotetext{
${ }^{2} \mathrm{O}$ termo "merge" tem sido traduzido, entre os gerativistas brasileiros, como "concatenar" por alguns, "conectar" por outros ou mesmo como "juntar" por outros deles. Estamos aqui utilizando o termo "soldagem/soldar", seguindo a sugestão de Donati (2008) que, em seu manual de introdução à sintaxe, vale-se do termo "salda" ("soldagem", em italiano), para fazer menção ao processo sintático do merge, que une dois objetos sintáticos, formando novo objeto complexo.

${ }^{3} \mathrm{O}$ texto utilizará o termo Middlefield em referência ao espaço da sentença onde se projetam as (cerca de) quarenta projeções funcionais da hierarquia de Cinque (1999). Tal espaço corresponde ao "TP", numa representação minimalista da estrutura. ${ }^{4}$ Usamos caixa alta para indicar o constituinte focalizado.
} 
O José gosta inclusive de sorvete.

O uso do advérbio em (5) tem também um efeito escalar: inferese que, além de outras coisas, José gosta de sorvete.

Uma vez que assumimos o princípio do "One Feature, One Head" já mencionado, esperamos que cada uma dessas classes de focalizadores ocupem uma posição específica na estrutura da oração. $\mathrm{Na}$ quarta seção, mostraremos que é este o caso: cada uma das cinco classes mencionadas nesta seção ocupam uma posição rígida e fixa na hierarquia dos constituintes do Middlefield.

Na próxima seção, faremos uma revisão da literatura sobre a Cartografia, com especial destaque aos constituintes do Middlefield ou espaço IP.

\section{Como chegar à hierarquia?}

Tomando como ponto de partida a distribuição relativa de advérbios de classes semânticas diferentes em várias línguas, Cinque (1999) propõe uma "explosão" do IP/TP (CHOMSKY, 1986, 1995) nas seguintes categorias funcionais, realizadas foneticamente, ou não, via AdvPs (em Spec) ou núcleos funcionais (" $\mathrm{X}^{\circ} \mathrm{s}$ "):

(5) A hierarquia dos advérbios e núcleos funcionais de IP

[francamente MoodspeechAct $>$ [surpreendentemente MoodEvaluative $>$ [supostamente MoodEvidential $>$ [provavelmente ModEpistemic $>$ [uma vez TPast $>$ [então TFuture $>$ [talvez Moodirrealis $>$ [necessariamente ModNecessity $>$ [possivelmente Modpossibility $>$ [normalmente AspHabitual $>$ [finalmente AspDelayed $>[$ tendencialmente AspPredispositional $>[$ novamente AspRepetitive(I) $>$ [frequentemente AspFrequentative (I) $>[$ de/com gosto Modvolition $>$ [rapidamente AspCelerative $(\mathrm{I})>[j a ́$ TAnterior $>[$ não ... mais AspTerminative $>[$ ainda AspContinuative $>$ [sempre AspContinuous $>$ [apenas AspRetrospective $>[($ dentro $)$ em breve AspProximative $>$ [brevemente AspDurative $>[(?)$ Aspgeneric/Progressive $>$ [quase AspProspective $>$ $[$ repentinamente Aspinceptive $(\mathrm{I})>[$ obrigatoriamente Modobligation $>[$ em vão/à toa AspFrustrative $>[(?)$ AspConative $>$ [completamente AspsgCompletive(I) $>$ [tudo AspPICompletive $>[$ bem Voice $>[$ cedo AspCelerative(II) $>[$ do nada AspInceptive(II) $>$ $\left[\right.$ de novo AspRepetitive(II) $>\left[\right.$ frequentemente AspFrequentative(II) $>\ldots{ }^{5}$

${ }^{5}$ A hierarquia universal foi originalmente apresentada por Cinque em 1999, e por ele modificada em 2006. A versão da hierarquia que aqui se apresenta com os advérbios 
Os advérbios em (5) ocupam uma posição fixa na estrutura e não se movem da posição em que foram inicialmente soldados, a não ser que tenham de valorar algum traço da estrutura informacional - Tópico, Foco, Modificação etc. (RIZZI, 2004). Desse modo, os advérbios servem como diagnósticos para o movimento de outros constituintes da sentença (por exemplo, V, auxiliares e modais, argumentos de V etc.).

A metodologia de Cinque (1999) para determinar a hierarquia apresentada em (5) consiste basicamente na utilização detestes de transitividade envolvendo advérbios de classes semânticas distintas. Deste modo, se um dado $\mathrm{AdvP}_{\mathrm{A}}$ precede (">>) um $\mathrm{AdvP}_{\mathrm{B}}$ qualquer, que precede, por sua vez, um $\mathrm{AdvP}_{\mathrm{C}}$, por transitividade chega-se à conclusão que o $\operatorname{AdvP}_{\mathrm{A}}$ precede o $\operatorname{AdvP}_{\mathrm{C}}$ :

$$
\begin{aligned}
& \text { a. } \operatorname{AdvP}_{A}>\operatorname{AdvP}_{B} \\
& \text { b. } * \operatorname{AdvP}_{B}>\operatorname{AdvP}_{A} \\
& \text { a. } \operatorname{AdvP}_{B}>\operatorname{AdvP}_{C} \\
& \text { b. } * \operatorname{AdvP}_{C}>\operatorname{AdvP} P_{B}
\end{aligned}
$$

$$
\text { Portanto: } \mathrm{AdvP}_{\mathrm{A}}>\mathrm{AdvP}_{\mathrm{B}}>\mathrm{AdvP}_{\mathrm{C}}
$$

O expediente do "teste de transitividade" é apresentado aos dados do inglês em (9-11), a seguir. Como se vê em (9), advérbios de ato de fala precedem AdvPs avaliativos. Esses últimos precedem os evidenciais (cf. (10)), os quais precedem os advérbios epistêmicos, como se vê em (11). Os exemplos são citados em Cinque (1999, p. 33):

(9) AdvPs de ato de fala (honestly) $>$ AdvPs avaliativos (unfortunately): a. Honestly I am unfortunately unable to help you. Honestamente eu sou infelizmente incapaz para ajudar você 'Honestamente, eu infelizmente não tenho condições de te ajudar' b. *Unfortunately I am honestly unable to help you Infelizmente eu sou honestamente incapaz de ajudar você

(10) AdvPs avaliativos (fortunately) > AdvPs evidenciais (evidently): a. Fortunately, he had evidently had his own opinion of the matter

em português se baseia (quase integralmente) em Santana (2005) e Tescari Neto (2013, 2015a,b). 
Felizmente, ele tinha evidentemente tido sua própria opinião do problema

'Felizmente, ele evidentemente tinha tido sua própria opinião do problema'

b. *Evidently he had fortunately had his own opinion of the matter Evidentemente ele tinha felizmente tido sua própria opinião do problema

(11) AdvPs evidenciais (clearly) > AdvPs epistêmicos (probably):

a. Clearly John probably will quickly learn French perfectly

Claramente John provavelmente vai rapidamente aprender francês perfeitamente

'Claramente, John provavelmente vai rapidamente aprender francês perfeitamente'

b. *Probably John clearly will quickly learn French perfectly

Provavelmente John claramente vai rapidamente aprender francês perfeitamente

Cinque (1999) repete esse mesmo expediente para as cerca de 30 classes de AdvPs para chegar à hierarquia em (5). A referida hierarquia, entretanto, não inclui posições para as classes de focalizadores descritas anteriormente. Será com base nos testes de transitividade que proporemos uma hierarquia para os AdvPs ditos focalizadores - entre si e em relação aos outros advérbios.

\section{E os AdvPs focalizadores? Que posições ocupam?}

Ainda que Cinque (1999) não tenha considerado os advérbios focalizadores em sua hierarquia universal, o autor defende que tais AdvPs sejam tratados conforme Bayer (1996) e Kayne (1998).

Kayne (1998) defende que o processo de atribuição de escopo a constituintes modificados por advérbios focalizadores se dá na sintaxe visível, através de soldagem interna, i.e., de movimento. Para o caso dos AdvPs ditos focalizadores, o advérbio ocuparia a posição de núcleo de uma projeção associada a foco dominando $v \mathrm{P}$. O constituinte associado ao AdvP focalizador, i.e., o XP por ele modificado, seria "atraído" ao seu especificador. O passo seguinte, na história derivacional, corresponderia ao movimento do advérbio ao núcleo da projeção imediatamente 
dominante ( $\mathrm{W}^{0}$ para Kayne), garantindo que, dessa posição, o AdvP focalizador c-comandaria o XP sob seu escopo. Esse deslocamento desencadearia o movimento do remanescente ao especificador de $\mathrm{W}^{0}$, restaurando a ordem dos constituintes antes desses passos derivacionais, criando a ilusão de ausência de movimentos (ver fig. 1).

Conforme mencionado em Tescari Neto (2015a: 577), Munaro (2011) também fornece um tratamento "cartográfico" para advérbios focalizadores. Para Munaro, um advérbio focalizador é inserido na posição de núcleo de uma projeção de foco das periferias (esquerda (CP) ou direita $(v \mathrm{P}))$. Para o autor, que também segue Kayne (1998), o focalizador atrairia o foco ao seu especificador (cf., na figura 1, a seguir, o passo derivacional representado por (1)), seguido pelo movimento do focalizador ao núcleo $\mathrm{W}^{0}$ imediatamente acima (2), e, na sequência, pelo movimento do remanescente (ver (3) na figura a seguir). O movimento do remanescente garantiria que apenas o XP sob o escopo do advérbio focalizador fosse c-comandado por ele. Embora à primeira vista a proposta de Munaro (2011) pareça atraente por sua simplicidade - já pelo fato de a focalização por AdvPs refletir o processo (mais) geral de focalização (com os AdvPs focalizadores ocupando a posição de núcleo de uma das duas projeções de foco da sentença) -, tal análise não fornece, conforme já apontado em Tescari Neto (2015a), uma motivação estrutural para a existência de uma hierarquia de diferentes classes semânticas de advérbios focalizadores, haja vista o fato de assumir apenas duas posições de Soldagem (Spec,vP e Spec,CP) para esses advérbios, independentemente de sua classe (semântica).

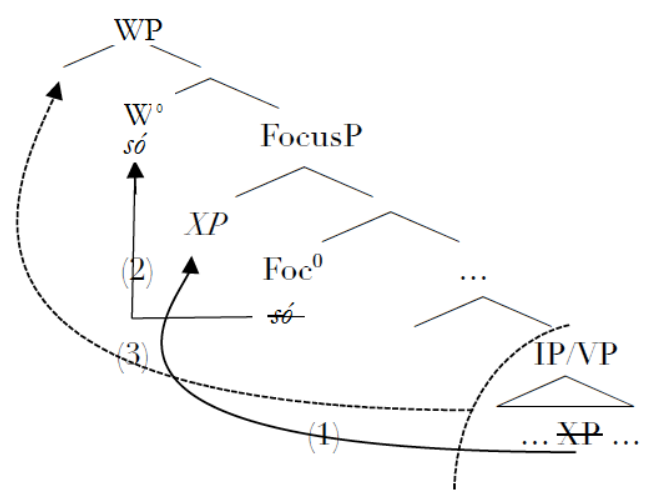

Figura 1 - Da atribuição de escopo a AdvPs focalizadores em Kayne (1998) e Munaro (2011)

Fonte: Tescari Neto (2015: 577) 
Também conforme apontado em Tescari Neto (2015a: 578), avanços recentes em Cartografia (CINQUE; RIZZI, 2010 e referências citadas lá) nos levam à seguinte indagação: "Qual/quais a(s) posição(posições) que as cinco diferentes classes (semânticas) de advérbios focalizadores mencionadas na anteriomente ocupariam em termos de hierarquias funcionais?" Para abordar a sintaxe dos advérbios focalizadores em consonância com os pressupostos da Cartografia é necessário reconhecer que cada uma das diferentes classes desses AdvPs teria uma posição distinta de Soldagem, atendendo ao princípio do "One Feature, One Head" (KAYNE, 2005). Este será o ponto de vista aqui assumido.

Os dados a seguir, amplamente discutidos em Tescari Neto (2015a: 578-580) e aqui repetidos, sugerem que diferentes classes de AdvPs focalizadores também se ordenam rigidamente entre si e em relação aos outros advérbios da hierarquia Cinque ${ }^{6}$ :

${ }^{6}$ Para os propósitos teórico-metodológicos do presente trabalho, sentenças do tipo de (ia) - ordem potencialmente alternativa a (12a) -, (ib) - ordem alternativa a (18a') -, (ic,d) - que se apresentam como alternativas à ordem em (19a) -, e (ie) - que se apresenta como alternativa a (20a) - devem ser desconsideradas por uma razão: as sentenças de (i) não formam pares mínimo com as sentenças em (12a, 18a', 19a e 20a) haja vista o fato de os advérbios das sentenças de (i) não estarem em contiguidade. A contiguidade é de suma importância em testes de transitividade à la Cartografia - estejam os AdvPs precedendo um auxiliar ou mesmo o V lexical, estejam os AdvPs precedendo um dos argumentos de V -, pois o movimento do remanescente, no espírito de Kayne (1998) supracitado, pode mascarar a ordenação dos AdvPs, criando a ilusão de que não é possível estabelecer uma ordenação rígida e fixa entre ambos. Por esse motivo, é necessário que os AdvPs estejam adjacentes (i.e., linearizados um ao lado do outro).

(i) a. O Mané até falaria só inglês se precisasse.

b. Ele talvez foi só para Cingapura.

c. O José provavelmente come só arroz.

d. O José só come provavelmente arroz.

e. O Mané já limpou só o banheiro.

Assim, dados como (i d,e) não seriam problemáticos para o extrato da hierarquia em (22), que será integrado à hierarquia dos advérbios de Cinque em (68), uma vez que os advérbios linearizados à esquerda em (i d,e) entraram na derivação antes dos linearizados à direita: sua linearização à esquerda de advérbios que os c-comandam na hierarquia em (22/68) é simplesmente o resultado do movimento do remanescente que carrega os advérbios só e já em (i d,e), criando a impressão de que seriam contraexemplos à 
(12) a. O Mané até só falaria inglês se precisasse [PB]

b. *O Mané só até falaria inglês se precisasse

(13) a. He'd even only speak English, if he had to (=12a)

b. *He'd only even speak English, if he had to (=12b) (KAYNE, 1998, p. 162, n. 83)

(14) a. Ti ho chiesto di leggere anche solo un capitolo [Italiano]

Te pedi para ler inclusive somente um capítulo

'Pedi que você lesse inclusive apenas um capítulo'

b. *Ti ho chiesto di leggere solo anche un capitolo (G. Cinque, comunicação pessoal)

(15) a. Ion manânca (chiar) si numai pâine [Romeno-A. Bleotu, com. pessoal]

I. come também só pão

'I. também só come pão'

b. *Ion manânca (chiar) numai si pâine

(16) a. [lian mohuoke zheme miren de yuyan $\left._{\mathrm{F} 1}\right]_{\mathrm{i},}$, ye zhiyou ${ }_{2}$ zhangsan $_{\mathrm{F} 2}$ zai yanjou $t_{\mathrm{i}}$

mesmo Mohawk bastante atrativa DE língua YE somente Z. Progressivo estuda

'Somente ${ }_{2}$ o Z $_{\mathrm{F}_{2}}{ }^{7}$ está estudando até mesmo ${ }_{1}$ Mohawk $_{\mathrm{F} 1}$, uma língua bem fascinante'

hierarquia universal. Para mais detalhes, mais adiante no texto, a derivação de (23c',c"), que revisita a análise de Kayne (1998).

Agradecimentos à/ao parecerista por ter apresentado as sentenças em (i), problematizando a validade da hierarquia apesar desses (aparentes) contraexemplos.

${ }^{7}$ Os índices $F_{1}$ e $F_{2}$ referem-se aos constituintes sob o escopo dos advérbios ('focalizadores') indicados respectivamente pelos índices 1 e 2 . Repare que, em chinês, a sintaxe visível deve espelhar a relação de escopo entre os focalizadores: assim, há um movimento pré Spell-Out de uma porção da oração, indicada pelo índice "i”, que contém o modificador 1 e o foco $\mathrm{F}_{1}$. Para a presente discussão, é importante frisar que a linearização " $\left[1 \mathrm{~F}_{1}\right]_{\mathrm{i}}\left[2 \mathrm{~F}_{2}\right] \ldots \mathrm{t}_{\mathrm{i}}$ " reflete exatamente uma hierarquia subjacente em que $\mathrm{Adv}_{1}>\mathrm{Adv}_{2}$ (que também vimos em (12-15)). 
b. * zhiyou $_{2}$ zhangsan $_{\mathrm{F} 2}\left[\operatorname{lian}_{1}\right.$ mohuoke zheme miren de yuyan $\left.{ }_{\mathrm{F} 1}\right]$ iye zai yanjou $t_{\mathrm{i}}$

( ${ }^{\mathrm{OK}}$ lian>zhiyou ; *zhiyou>lian [Chinês (SHU, 2011, p. 124)]

(17) a. Chulsu-nun yeksi tansunhl uss-ess-ul kussita[Coreano]

C. -tópicotambém meramente/só sorrir-pass-EPIST

Chulsu também só sorriu'

b. Chulsu-nun tansunhl *(,) yeksi uss-ess-ul kussita (Sung Yun Cho, com. pes.)

(18) a. ta shuobuding zhi qu-guo xinjiapuo [Chinês (SHU, 2011, p. 160)] ele talvez só ir-Exp Cingapura

'He tinha talvez só ido a Cingapura'

b. *ta zhi shuobuding qu-guo xinjiapuo

a'. Ele talvez só foi para Cingapura $(=7 \mathrm{a}, \mathrm{b})$

b'. *Ele só talvez foi para Cingapura ${ }^{8}$

(19) a. O José come provavelmente só arroz

b. *O José come só provavelmente arroz

(20) a. O Mané só já limpou o banheiro

b. *O Mané já só limpou o banheiro

(21) a. Ha solo già mangiato la pasta [Italiano]

(Ele/ela)-tinha só já comido a massa

'Ele/ela só já comeu massa'

b. *Ha già solo mangiato la pasta (Guglielmo Cinque, com. pessoal)

${ }^{8}$ Os dados (18a',b’) são discutidos em Tescari Neto (2015a). Um dos pareceristas anônimos daquele trabalho sugere, a propósito da discussão sobre (18a',b’), que (i.b), a seguir, é apenas marginal, mas não agramatical:

(i) a. Ele talvez só tenha ido à padaria.

b.?Ele só talvez tenha ido à padaria.

Para nós, (i.b) é agramatical, a não ser que só seja de alguma forma "prosodicamente marcado". Para os propósitos deste trabalho, ao produzir julgamentos de gramaticalidade, é importante criar "pares mínimos reais', i.e., sentenças com entoação "plana" ("flat intonation"). Se o só em (b) é prosodicamente marcado, (b) não forma par mínimo com (a) e as duas sentenças devem ser descartadas da amostra. 
Conforme aponta Tescari Neto (2015a: 579), os dados em (12-21) nos levam a (22):

(22) (i) provavelmente/talvez $>$ só $>$ já

(ii) também > só

Em relação às sentenças apresentadas em (12-21), é importante observar que estamos assumindo, na esteira de Cinque (1999) e do Programa Cartográfico - ver detalhes em Tescari Neto (2013; 2015a,b) que os advérbios em questão ocupam posições rígidas e fixas de especificadores em nível sentencial e não posições de adjunção a DPs e outros constituintes da estrutura da oração. Assim, cada advérbio será sempre Soldado numa mesma posição na oração, salvos naturalmente os casos de homonímia para os quais uma mesma forma lexical poderia ser soldada em mais de uma posição, com especificações semânticas para cada uma das posições distintas - ver o caso dos advérbios "reduplicados", com índices I e II na hierarquia apresentada em (5), em que o mais alto toma sob o seu escopo o evento e o mais baixo, de índice II, o processo ${ }^{9}$.

Para além do que foi apontado no parágrafo anterior, conforme apontado também em Tescari Neto (2015a: 580), a sentença (23c) e ocorrências similares - não só no $\mathrm{PB}$, mas também no português europeu (PE) - são ambíguas: os advérbios em (c) podem, em uma leitura, modificar apenas o DP (como se vê pela paráfrase em (23c'), leitura que aqui denominamos de 'foco estreito'), mas podem, numa outra, também modificar todo o VP (dada a aceitabilidade de (23c"), leitura aqui denominada de 'foco largo' ou foco 'sobre o VP').

c. O José comeu provavelmente só arroz

c'. O José comeu provavelmente só arroz, não feijão (foco estreito)

c”. O José comeu provavelmente só arroz, não bebeu leite (foco largo)

Parece-nos, então, ser muito mais vantajoso entender que ambas as interpretações para (23c), i.e., (23c') e (23c"), tenham uma mesma história derivacional, com a subida do constituinte sob o escopo do(s)

${ }^{9}$ Ver Tescari Neto (2013, p. 240) para casos aparentemente problemáticos. 
$\operatorname{AdvP(s)~ao~Spec~de~um~núcleo-probing~atrator,~}{ }^{10}$ seguido pela Soldagem do AdvP no Spec da projeção imediatamente dominante e ulterior movimento do material remanescente (ao Spec imediatamente acima), no espírito de Kayne (1998) (ver também Ambar (2008), cuja proposta para os advérbios confirmativos do PE se assimila a de Kayne). Deste modo, para as sentenças de (23), tem-se a repetição do mesmo processo derivacional toda vez que um dos AdvPs focalizadores é Soldado: há um movimento do constituinte a ser focalizado ao Spec do núcleo-probing associado a só, com posterior Soldagem de só no Spec da projeção acima e subida do remanescente ao Spec que c-comanda imediatamente este advérbio. Os mesmos passos derivacionais se repetem quando da entrada de provavelmente na derivação: há um movimento do constituinte formado por só mais o DP sob o seu escopo ao especificador do núcleoprobing associado ao advérbio provavelmente; na sequência, tem-se a

\begin{abstract}
${ }^{10}$ Em Kayne (1998), esse núcleo atrator seria lexicalizado pelo próprio advérbio dito focalizador, que, após o movimento do foco a seu especificador, também se moveria, adjungindo-se ao núcleo imediatamente acima. A modificação feita aqui - que mantém alguns aspectos cruciais da derivação de Kayne - se diferencia da proposta deste autor apenas pelo fato de que o núcleo atrator não seria preenchido pelo advérbio focalizador em si, mas por um núcleo não pronunciado em português. O AdvP entraria na derivação no Especificador da projeção imediatamente acima (basta aplicar testes tradicionais para concluir que AdvPs focalizadores são XPs e não $\mathrm{X}^{0} \mathrm{~s}$ - ver Tescari Neto, 2013, p. 91). Há interessante evidência para assumir que o núcleo atrator não seria o advérbio focalizador, mas uma partícula associada a foco. Segundo Shu (2011, p. 132), existe, em mandarim, um marcador de concordância, $C A I$, que pode aparecer com um advérbio focalizador:
\end{abstract}

(i) Chinese (SHU 2011, p. 132)

A: zhangsan changchang mai xigua

'Zhangsan frequentemente compra melões'

B: - bu. ta zhi(you) $)_{1}\left[\text { ouer }_{2}\right]_{\mathrm{F} 1}$ cai mai xigua ${ }_{\mathrm{F} 2}$.

Não ele sóalgumas vezes CAI compra melões

'Não. Ele só ${ }_{1}$ compra melões ${ }_{\mathrm{F} 2}$ ocasionalmente [occasionalmente $\left._{2}\right]_{\mathrm{F} 1}$ '.

O ponto interessante aqui é que essa partícula cai aparece sempre imediatamente à direita do foco, i.e., ela sinaliza a borda direita do constituinte focalizado. Parece correto, portanto, tomar essa partícula como sendo o núcleo atrator do foco, que se associa necessariamente a um advérbio que entra na derivação no Spec da projeção imediatamente acima. Em PB, no entanto, esse núcleo é silencioso. 
Soldagem de provavelmente, seguida pelo movimento do remanescente ao Spec imediatamente acima. ${ }^{11}$

As figuras 2 e 3 ilustram a derivação de (23) na leitura em que os advérbios têm foco estreito (23c').

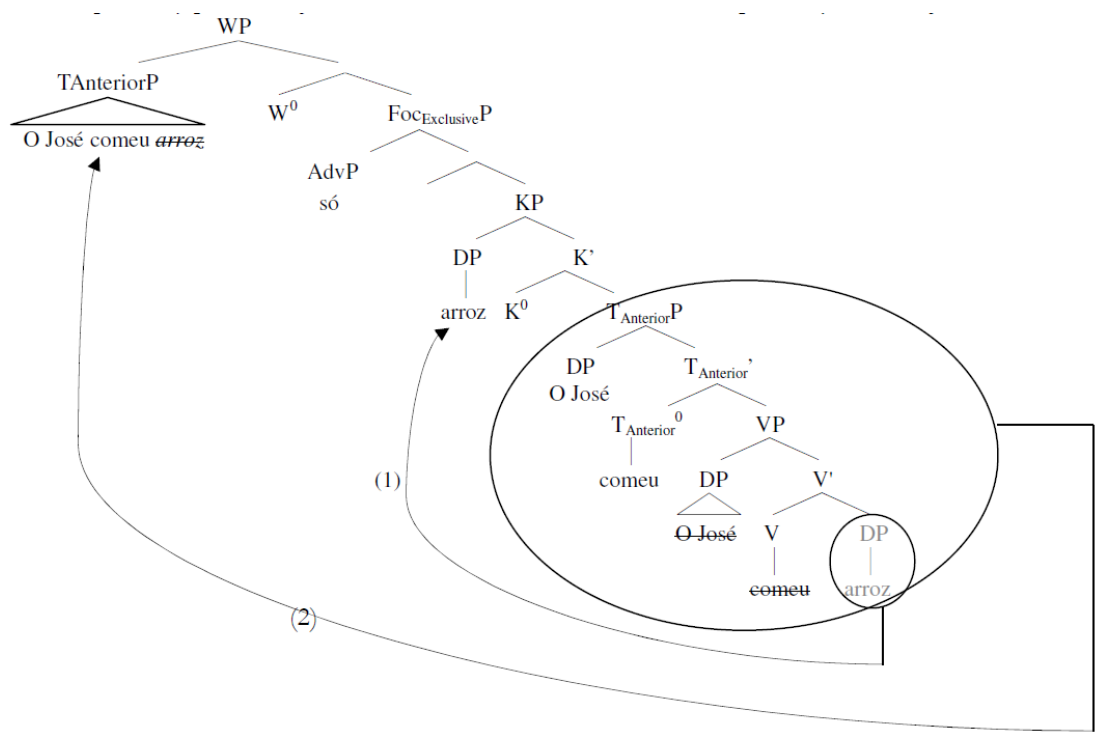

Figura 2 - A derivação de (23c) na leitura de foco estreito $\left(23 c^{\prime}\right)$ - parte $\mathrm{I}^{12}$

Fonte: elaborada pelo autor

${ }^{11}$ Os dados (12-21) deixam claro que provavelmente precede só, motivo por que só entra primeiro na derivação. Ficará claro nesta seção e na próxima que provavelmente ocupa uma posição bem mais alta do que a de só.

${ }^{12} \mathrm{Um}$ dos pareceristas indagou, acerca da representação das derivações esquematizadas nas figuras 2 e 3, qual seria a natureza de KP, WP, $\mathrm{K}_{1} \mathrm{P}$ e $\mathrm{W}_{1} \mathrm{P}$. KP seria a projeção que sempre entraria na derivação antes que um advérbio alto - associado a foco - fosse Soldado. Na presença de dois advérbios associados a foco, seriam necessárias duas projeções KP (por isso, a segunda delas a entrar na derivação foi aqui denominada de "K $\mathrm{P}_{1}$ ”). Em teoria, haverá tantas KP quantos forem os advérbios associados ao foco presentes na numeração. A nota 10 oferece evidência empírica sobre a realização morfofonológica de K no mandarim. Sobre a natureza (teórico-conceitual) de W, remete-se o leitor a Kayne (1998, 2005). Munaro (2011) oferece evidências de sua realização em dialetos italianos. Para ulteriores informações acerca de tais projeções, Tescari Neto (2013).

Um outro ponto mencionado pela/o parecerista indaga justamente a possibilidade de o DP o arroz, da fig. 2, se mover diretamente a [Spec, FocP] na periferia esquerda. O 


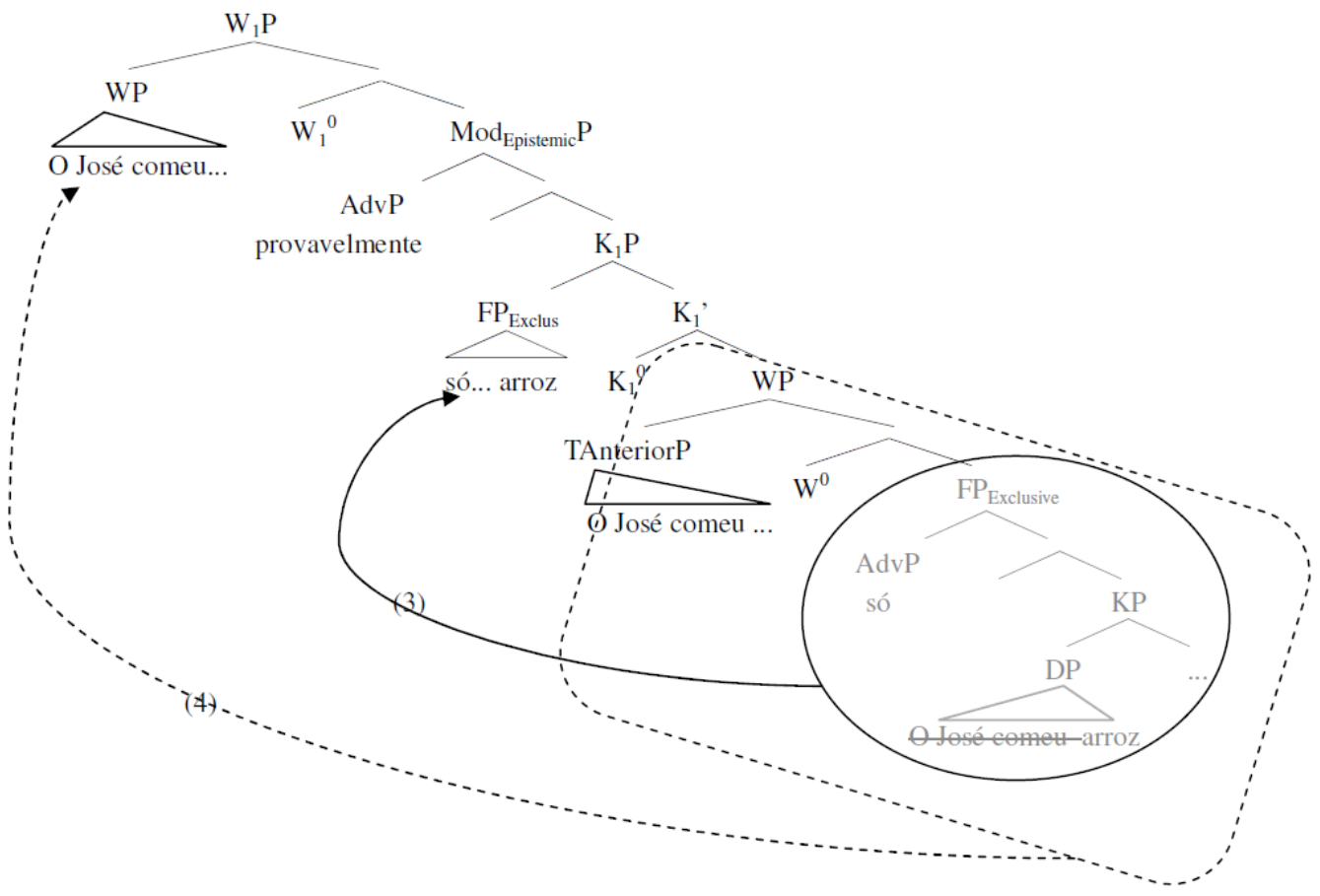

Figura 3 - A derivação de (23c) na leitura de foco estreito (23c') - parte II Fonte: elaborada pelo autor

As figuras 4 e 5, por sua vez, ilustram a derivação da leitura de "foco largo" para os advérbios, i.e., de escopo sobre todo o VP, conforme a paráfrase (23c"), repetida a seguir.

(23) c’. O José comeu provavelmente só arroz, não bebeu leite. (foco largo)

movimento ao especificador do núcleo atrator (aqui, [Spec, KP]) é necessário para que, nesta configuração, o DP o arroz fique sob o escopo do advérbio só, sendo o escopo definido em termos de c-comando. Haverá, sim, movimento à periferia esquerda, a [Spec, FocP], todavia ao final da derivação, para a valoração dos traços de [foco]. O movimento a [Spec,KP] é motivado por razões de atribuição de escopo na sintaxe visível (no espírito de Kayne, 1998, revisitado). Ver, a esse respeito, Quarezemin e Tescari Neto (2015). 
É importante notar que, no caso da leitura de foco largo, i.e., de foco sobre todo o VP, o que garante que todo o VP esteja sob o escopo dos AdvPs provavelmente e só, apesar de apenas o DP ser linearizado em $\mathrm{PF}$ à direita dos $\mathrm{AdvPs}$, é a presença de uma cópia não pronunciada do $\mathrm{V}$ comeu no especificador do núcleo atrator. Esta cópia não pronunciada do V é, então, reconstruída no especificador do núcleo-probing, garantindo a leitura de escopo $\operatorname{largo} 0^{13,14}$.

${ }^{13} \mathrm{Uma} /$ um parecerista anônima/o questionou “que mecanismo vai garantir a reconstrução do verbo especificamente em AspP (uma posição intermediária na cadeia criada pelo movimento do núcleo) e não em VP (na cauda da cadeia)". Conforme a representação da derivação de (23c), na leitura em que se tem escopo largo (23c") - fig. 4 -, não é a cópia de $\mathrm{V}$ na posição intermediária $\mathrm{Asp}^{\circ}$ que se reconstrói, mas a cópia em $\mathrm{V}^{\mathrm{o}}$, posição de Soldagem externa do verbo, que foi deslocada como parte de um bloco maior, aqui identificado como AspP. A cópia que se reconstrói em [Spec,K], portanto, é a cópia mais baixa, a cauda da cadeia, não a intermediária (ver, na figura 4, pelo passo derivacional identificado como "(1)", que AspP faz o pied-piping de todo o bloco por ele c-comandado, que contém a cauda a ser reconstruída).

${ }^{14}$ Dados sobre a elipse de VP em português deixam claras as vantagens da assunção deste Kayne revisitado face às propostas concorrentes sobre a adjunção direta do advérbio a qualquer XP suscetível de modificação. Enquanto advérbios baixos e mediais, se presentes no primeiro membro de uma coordenação, podem ou não ser recuperados no segundo membro ((i-ii), a seguir), advérbios altos não são jamais recuperáveis pelo VP-elíptico ((iiia), abaixo); neste caso, apenas a construção de complemento nulo, que não envolve elipse de VP, é possível (iiib).

(i) O Eduardo limpou cuidadosamente o banheiro e o Anderson também limpou [-].

a. [-]: limpou cuidadosamente o banheiro (elipse de VP)

b. [-]: limpou o banheiro (complemento nulo)

(ii) O Eduardo limpou o banheiro cedo e o Anderson também limpou [-].

a. [-]: limpou o banheiro cedo. (elipse de VP)

b. [-]: limpou o banheiro. (complemento nulo)

(iii) O Eduardo limpou provavelmente o banheiro e o Anderson também limpou [-].

a. *[-]: limpou provavelmente o banheiro. (elipse de VP)

b. [-]: limpou o banheiro (complemento nulo)

Os advérbios baixos (cuidadosamente (ia), cedo (ib)) são recuperáveis pelo VP-elíptico, diferentemente do que se observa em (iiia), cujo advérbio alto não é nunca recuperável, uma vez que o advérbio alto se encontra numa posição mais alta que a altura (máxima) de pouso do V no Middlefield. Tais fatos são facilmente capturados numa representação cartográfica 


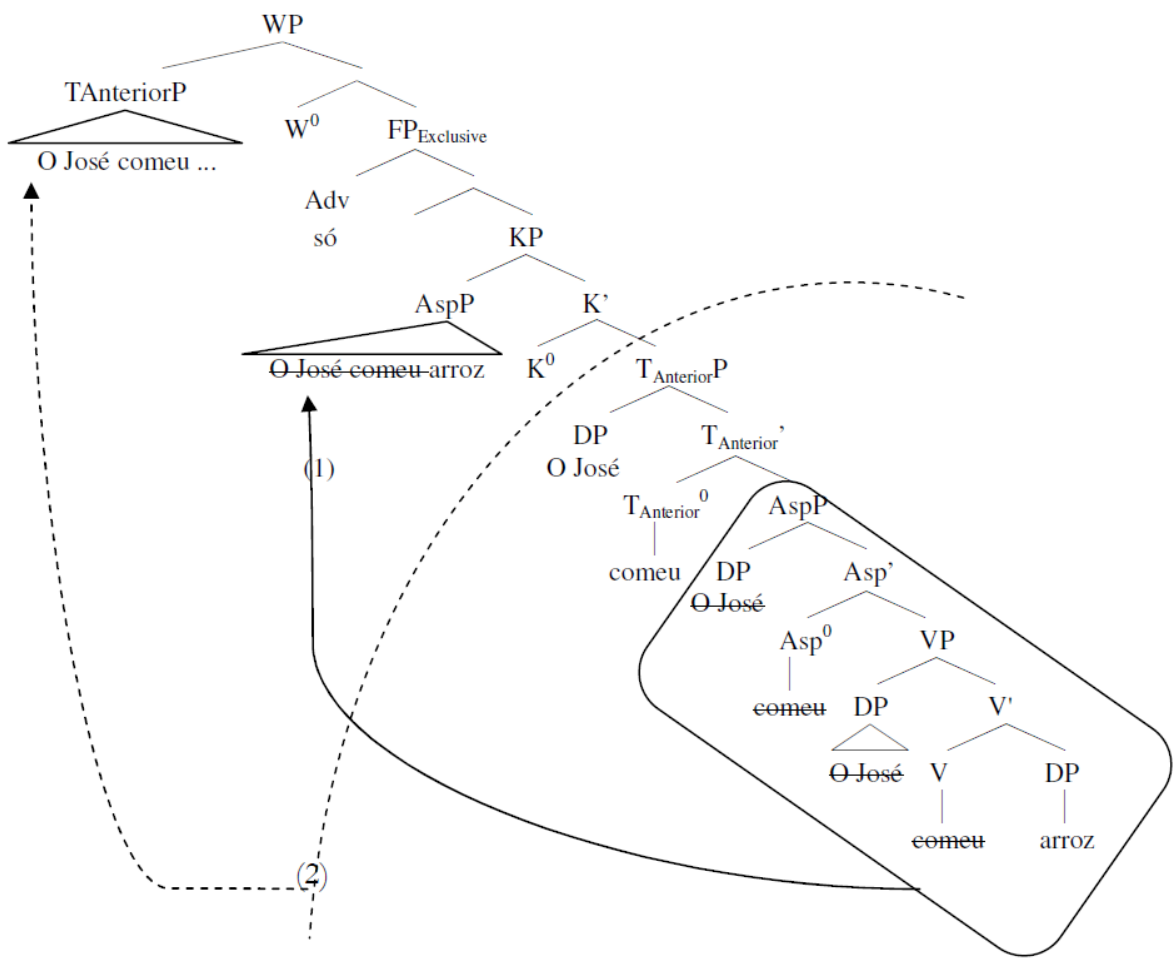

Figura 4 - A derivação de (23c) na leitura de escopo largo (23c") - parte I Fonte: elaborada pelo autor

Conforme dissemos em outra oportunidade (cf. Tescari Neto, 2015a:581), não há razão para distinguir advérbios que atuam como modificadores da sentença de advérbios de constituintes no que diz respeito à posição que ocupam na estrutura (i.e., em relação à porção da estrutura à qual são "adjungidos"). O que conta para o "cálculo do escopo" do advérbio é a porção da estrutura que vem a ocupar o Spec do núcleoprobing associado ao AdvP e Soldado antes dele na derivação. Nos casos

da estrutura e dos adjuntos, se se assume também a proposta de Kayne (revisitada), como se propõe aqui. Análises que advogam em favor da adjunção direta do AdvP ao XP sob seu escopo, como Zyman (2012), por exemplo, fazem previsões equivocadas sobre (iii): esperar-se-ia, por tais análises, que o advérbio alto fosse recuperável pelo VP-elíptico, por se adjungir diretamente ao DP sob seu escopo, o qual necessariamente é c-comandado pelo verbo em INFL. Para mais detalhes, Tescari Neto $(2013 ; 2015 b)$. 


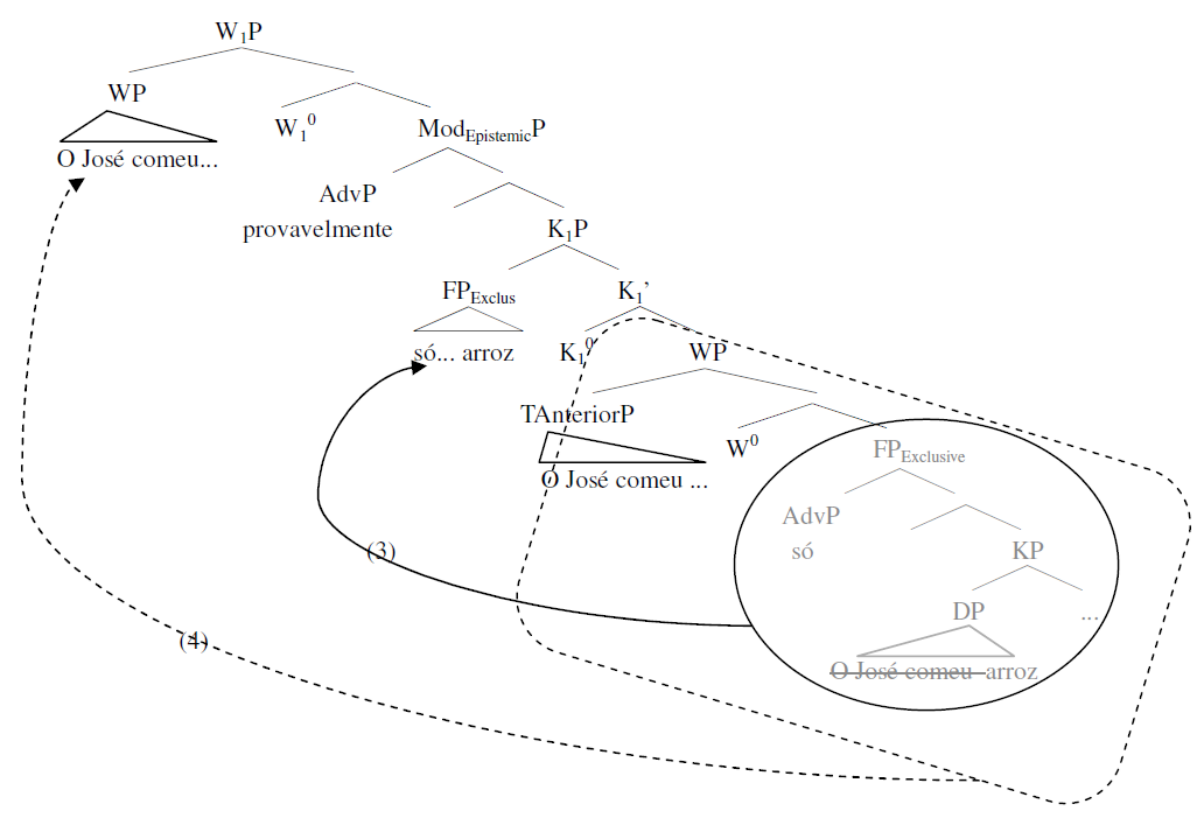

Figura 5 - A derivação de (23c) na leitura de escopo largo (23c") - parte II Fonte: elaborada pelo autor

em que apenas o DP-complemento se move ao especificador em questão, tem-se o "foco estreito" (cf. (23c')). Quando o constituinte movido ao Spec do núcleo atrator contém uma cópia não pronunciada do verbo que, por razões independentes ligadas à subida do verbo (POLLOCK, 1989; CYRINO, 2013), se elevou a uma posição em INFL -, obtém-se uma interpretação segundo a qual o advérbio toma por escopo todo o VP (interpretação a que se denominou de "escopo largo" (ver (23c"), acima), dada a reconstrução da cópia do V no Spec do núcleo-probing. ${ }^{15}$

\footnotetext{
${ }^{15} \mathrm{Uma} / \mathrm{um}$ parecerista questionou qual seria a vantagem da proposta que aqui se faz frente às concorrentes, uma vez que, "no fim das contas, o AdvP vai ter escopo sobre um DP quando ele tiver um DP 'perto' dele e terá escopo sobre um VP quando tiver um constituinte que domina uma cópia de V que será reconstruída em LF 'perto' dele". Se se pensa nos fatos sobre a elipse de VP, mencionados na nota 14, a vantagem parece bastante clara: apenas advérbios c-comandados pelo $\mathrm{V}$ movido a uma posição da flexão são recuperáveis pelo VP-elíptico. Advérbios altos não são jamais recuperáveis. Alternativas concorrentes sobre a adjunção direta do advérbio ao XP sob seu escopo,
} 


\section{A posição dos AdvPs focalizadores na hierarquia universal}

Conforme mencionado anteriormente, Quirk et al. (1976), Ricca (1999), Adorno (2000), Shu (2011), Ferrari, Giammatteo e Albano (2011), dentre outros, reconhecem as seguintes classes de AdvPs focalizadores:

(i) os restritivos de exclusão: só, exclusivamente, meramente etc.;

(ii) os restritivos particularizadores: especialmente, principalmente etc.;

(iii) os aditivos escalares: até, até mesmo, mesmo etc.;

(iv) os aditivos não escalares: também etc.;

(v) os inclusivos: inclusive.

Com os avanços recentes das pesquisas em Cartografia das estruturas sintáticas, uma indagação interessante se coloca diante da subclassificação dos AdvPs focalizadores em (i-v) acima: Qual posição ou quais posições os advérbios em (i-v) ocupam na hierarquia universal dada em (5)? Uma maneira de abordar a sintaxe de advérbios focalizadores seguindo o Programa Cartográfico seria reconhecendo que cada uma dessas diferentes classes de AdvPs teria uma posição distinta de Soldagem, em consonância com o já citado princípio do "One Feature, One Head" (KAYNE, 2005), tão caro a abordagens cartográficas para a sintaxe. Assim, cada uma das cinco classes de focalizadores assinalada em (i-v) teria uma posição rígida e fixa na hierarquia em (5).

E como chegar à hierarquia dos AdvPs focalizadores? Seguindo a metodologia cartográfica de Cinque, basta tomar dois AdvPs por vez,

as quais geram a ordem linear "de saída ao assumir diferentes seleções para advérbios: seleção de DP ou de VP" - conforme aponta a/o parecerista -, fazem previsões equivocadas sobre os fatos da elipse de VP, por suporem que um advérbio alto possa ser recuperado nos casos de foco estreito, i.e., quando se "adjunge diretamente ao DP". Para além desta desvantagem, a teoria da adjunção precisaria recorrer a expedientes ad hoc para explicar a ordenação hierárquica dos advérbios, cuja proposta aqui assumida, a de Cinque (1999), consegue derivar naturalmente. Há, na verdade, um feixe de propriedades sintáticas que a assunção das hierarquias cartográficas e da análise revisitada de Kayne (1998) sobre a atribuição de escopo conseguem explicar sem a necessidade de recorrer a expedientes ad hoc: (i) a hierarquia dos advérbios - não obstante a existência de aparentes contra-exemplos (como (id,e) da nota 6) -, (ii) os fatos sobre a elipse de VP e (iii) as diferentes propriedades sintáticas de advérbios altos e baixos - que, por limitações de espaço não serão discutidas aqui (para isso, Tescari Neto, 2015a). 
colocando-os em adjacência nas duas ordens logicamente possíveis (i.e., $\left.\mathrm{Adv}_{\mathrm{A}}-\mathrm{Adv}_{\mathrm{B}} ; \mathrm{Adv}_{\mathrm{B}}-\mathrm{Adv}_{\mathrm{A}}\right)$. Com a combinação dos resultados parciais dos testes de transitividade, será possível chegar a uma hierarquia de advérbios focalizadores.

Nas sentenças (12-21), colocamos pelo menos um advérbio dito focalizador para co-ocorrer com um outro advérbio. Os resultados foram agramaticais para a ordem dita não hierárquica e gramaticais para a ordem hierárquica. Mas há um detalhe metodológico importante a ser observado aqui. Para explicitá-lo, vamos considerar as ocorrências em (24), que envolvem o advérbio tardio finalmente e o advérbio de exclusão só.

(24) a. O João finalmente só fez a capa do trabalho (TESCARI NETO, 2015a)

b. *O João só finalmente fez a capa

c. O João finalmente fez só a capa

Embora consideremos gramatical a sentença (24a), é importante lembrar que alguns falantes a consideram marginal (ver discussão em Tescari Neto, 2015a). ${ }^{16}$ Todavia, mesmo aqueles que a consideram degradada oferecem julgamentos distintos a $(24 a, b)$ : para eles, (a) é menos degradada do que (b), esta última sendo considerada completamente agramatical.

Conforme já discutido na nota 6 - ver também Tescari Neto (2015: 583) -, sentenças como (24c) devem ser desconsideradas dos dados: (24c) não forma par mínimo com (24b), pois os advérbios de (24c) não estão um ao lado do outro. Do ponto de vista metodológico, tal contiguidade é de suma importância - tanto nos casos em que os advérbios precedem um auxiliar ou o verbo principal, quanto nos casos em que precedem um dos argumentos de $\mathrm{V}-$, uma vez que a subida do material remanescente pode mascarar a ordem dos advérbios, dando-nos a impressão de que é impossível estabelecer uma ordenação rígida e fixa entre ambos. Isso explica a necessidade metodológica da contiguidade entre os advérbios em questão.

Feitas essas (importantes) observações metodológicas, podemos iniciar os testes de transitividade envolvendo os advérbios ditos

\footnotetext{
${ }^{16}$ Para alguns falantes, (24a) é marginal "depois de muita insistência”. Ver a discussão do dado (ia), na nota 3 de Tescari Neto (2015a).
} 
focalizadores. Tomando por primeiro os advérbios de inclusão (inclusive) e os particularizadores (particularmente, primeiramente, principalmente etc.), aqueles precedem estes na hierarquia, haja vista as combinações em $(25-26){ }^{17}$

(25) a. O João adora inclusive principalmente/primeiramente banana a'. Juan adora incluso principalmente los plátanos

b. *O João adora principalmente/primeiramente inclusive banana b'. *Juan adora principalmente incluso los plátanos ${ }^{18}$

(26) a. O João esquece inclusive principalmente a data de aniversário da esposa

a'. Juan olvida incluso especialmente la fecha de cumpleaños de la esposa

b. *O João esquece principalmente inclusive a data de aniversário da esposa

\footnotetext{
${ }^{17}$ Daqui por diante nesta seção, os dados em (a,b) são do PB e os dados em (a',b') a versão correspondente em espanhol de Lima/de Buenos Aires, o que dispensa glosas. Quando houver diferença no julgamento oferecido pelo informante de Lima e pelos informantes de Buenos Aires, faremos a observação relevante em nota ou no próprio texto.

${ }^{18}$ Onde se lê "los plátanos" ('as bananas') na versão limenha, leia-se "las bananas" na versão correspondente do espanhol de Buenos Aires:
}

(i) a. ?Juan adora incluso principalmente las bananas

b. *Juan adora principalmente incluso las bananas

Repare que, apesar de uma informante de Buenos Aires considerar a sentença em (a) não muitíssimo bem formada, ela percebe um contraste entre as versões (a) e (b), julgando como completamente agramatical a sentença (b), o que vai ao encontro dos julgamentos das versões em PB e em espanhol limenho, de (25). Repare que, para (ii) - que apresenta os mesmos advérbios de (i) e corresponde às versões em (26a,a';b,b') -, o contraste é bastante claro: (ii.a), a ordem hierárquica, é gramatical (como no PB, (26a), e no espanhol limenho, (26a')); (ii.b), que apresenta os advérbios 'desordenados' em relação à hierarquia a que se chegará ao final desta seção, é agramatical, como os correspondentes (26b,b').

(ii) a. Juan recuerda incluso especialmente la fecha de cumpleaños de su esposa Juan lembra inclusive especialmente da festa de aniversário da esposa dele b. *Juan recuerda especialmente incluso la fecha de cumpleaños de su esposa 
b'. *Juan olvida especialmente incluso la fecha de cumpleaños de la esposa

Os testes de transitividade em (25-26) nos levam a (27):

(27) inclusão > particularizadores

Se combinamos os AdvPs restritivos particularizadores (particularmente/principalmente) e os AdvPs restritivos de exclusão (só) numa mesma sentença, apenas a ordem particularizadores $>$ exclusão é possível (28-29), o que nos permite chegar a (30).

(28) a. O João adora particularmente/principalmente só banana

a'. Juan adora especialmente solo los plátanos

b. *O João adora só particularmente/principalmente banana

b'. *Juan adora solo especialmente los plátanos

(29) a. O João esquece particularmente/principalmente só a data de aniversário da esposa

a'. Juan olvida particularmente solo la fecha de cumpleaños de la esposa

b. *O João esquece só principalmente/particularmente a data de aniversário da esposa

b'. Juan olvida solo particularmente la fecha de cumpleaños de su esposa

(30) particularizadores $>$ de exclusão

Os testes de transitividade envolvendo um advérbio aditivo escalar (até) e um advérbio de inclusão (inclusive) (31-32) mostram que os advérbios de inclusão precedem os aditivos escalares (33).

(31) a. O João adora inclusive até banana

a'. Juan adora incluso hasta los plátanos

b. */?O João adora até inclusive banana

b'. *Juan adora hasta incluso los plátanos

(32) a. O João esqueceu inclusive até a data de aniversário da esposa

a'. Juan se olvidó incluso hasta la fecha de cumpleaños de su esposa 
b. *O João esqueceu até inclusive a data de aniversário da esposa b'. *Juan se olvidó hasta incluso la fecha de cumpleaños de su esposa

(33) inclusão > aditivo escalar

O mesmo advérbio aditivo escalar (até, hasta), se combinado com o advérbio de exclusão só/solo, resulta em gramaticalidade na ordem até/hasta > só/solo:

a. O Mané até só falaria inglês, se precisasse

a'. ?Juan hablaría hasta solo inglés, si lo necesitara

b. *O Mané só até falaria inglês, se precisasse

b'. *Juan hablaría solo hasta inglés, si lo necesitara ${ }^{19}$

Os dados em (34) - bem como aqueles apresentados em (13) e

${ }^{19}$ Para o informante de Lima, a única combinação possível dos advérbios aditivo escalar hasta 'até' e do advérbio de exclusão solo 'só' é na ordem solo > hasta (ver (i.b), abaixo), ordem surpreendentemente diferente da observada no espanhol de Buenos Aires e em PB ((34) no texto):

(i) a. *Juan hablaría hasta solo inglés si lo necesitara

b. Juan hablaría solo hasta inglés

Duas hipóteses poderiam explicar essa diferença: talvez o informante de Lima esteja considerando que o advérbio hasta tenha algum outro valor semântico diferente do valor de aditivo escalar. Ricca (1999) aponta para a polissemia do correspondente anche em italiano, especialmente quando este se combina com solo, como parece ser o caso de (i) em espanhol. A única possibilidade, para Ricca, seria a ordenação anche solo ('hasta solo'/'até só') necessariamente nesta ordem. Mas aí o valor do composto é o de um único item lexical. A outra possibilidade seria a de a derivação do informante de Lima ter envolvido o movimento de solo junto com o material remanescente, à esquerda de hasta, muito embora este último tenha entrado na derivação depois de solo, seguindo a ordem hierárquica.

O importante é que os correspondentes em PB e espanhol de Buenos Aires (34) e em inglês e italiano (as sentenças (13) e (14)) são possíveis apenas na ordem que aqui denominamos de 'hierárquica', i.e., até/hasta/even/anche $>$ só/solo/only/solo. Ainda que Kayne perceba alguma degradação em (13a), aquela sentença - que apresenta a ordem 'hierárquica' - é sensivelmente muito melhor do que (13b) que é agramatical. 
(14) - sugerem que o aditivo escalar precede o advérbio de exclusão:

(35) aditivo escalar $>$ de exclusão

A combinação de (27, 30, 33 e 35) nos leva ao estrato (parcial) da hierarquia de advérbios focalizadores em (36):

(36) inclusão > particularizadores/aditivo escalar > de exclusão

Como se conclui por (36), resta saber se os particularizadores precedem ou seguem os aditivos escalares. Tanto em PB (37a,b) quanto no espanhol (37a',b'), a única combinação possível desses advérbios em adjacência é a que envolve a ordem particularizador > aditivo escalar:

(37) a. O João falaria particularmente até o inglês, se precisasse a'. Juan hablaría particularmente hasta inglés si lo necesitara

b. *O João falaria até particularmente o inglês, se precisasse b'. *Juan hablaría hasta particularmente inglés si lo necesitara

Tendo em vista as combinações em (37), (36) pode ser reformulado conforme (38):

(38) inclusão $>$ particularizadores $>$ aditivo escalar $>$ de exclusão inclusive $>$ particularmente $>$ até $>$ só $(\mathrm{PB})$ incluso $>$ particularmente $>$ hasta $>$ solo (Espanhol)

Resta ainda verificar a posição dos aditivos não escalares do tipo de também. Repare que este advérbio pode tomar por escopo uma parte do VP que o segue (39), todo o VP que o segue (40) ou o sintagma que o precede $(41 \mathrm{a}, \mathrm{b})$ :

(39) O João também esqueceu a data do aniversário, não do casamento

(40) O João também esqueceu a data do aniversário, não lembrou

(41) a. O João também (não o Pedro) esqueceu a data do aniversário b. O João esqueceu também (não lembrou) a data do aniversário 
Devido a dados como (39), determinar a posição de também relativamente aos outros focalizadores discutidos até então é uma atividade complexa. Para casos como (40), em que o advérbio está associado ao VP, parece que também é mais alto que até, se cuidarmos para que o escopo deste último também seja o VP, como em (41b). Essa conclusão vem da combinação de (40) e (42) mostrada em (43).

(42) O João até esqueceu a data do aniversário, não lembrou

(43) a. O João também até esqueceu a data do aniversário, não lembrou b. *?O João até também esqueceu a data do aniversário, não lembrou

No espanhol de Lima, o aditivo não escalar también 'também' deve também preceder o aditivo escalar hasta:

(44) a. Juan olvidó también hasta la fecha del cumpleaños no del casamiento

Juan esqueceu também até a festa de aniversário, não do casamento

b. *Juan olvidó hasta también la fecha del cumpleaños no del casamiento

(45) aditivo não escalar $>$ aditivo escalar

Em relação ao advérbio de inclusão inclusive/incluso, este deve necessariamente preceder o advérbio não escalar também:

(46) a. O João esqueceu inclusive também a festa de aniversário, não a do casamento

a'. Juan olvidó incluso también la fecha del cumpleaños no del casamiento

b. *O João esqueceu também inclusive a festa de aniversário, não a do casamento

b'. *Juan olvidó también incluso la fecha del cumpleaños no del casamiento 
(47) de inclusão > aditivo não escalar ${ }^{20}$

Combinando (38), (45) e (47), chega-se à hierarquia em (48):

(48) de inclusão $>$ particularizadores/aditivo não escalar $>$ aditivo escalar $>$ de exclusão

Falta, então, determinar a posição dos particularizadores relativamente ao aditivo não escalar. A julgar por (49), os particularizadores precederiam o aditivo não escalar também na hierarquia:

(49) a. O João prefere particularmente também as bananas

b. ${ }^{* / ?} \mathrm{O}$ João prefere também particularmente as bananas

(50) particularizadores > aditivo não escalar

A combinação de (48) e (50) levaria à seguinte hierarquia para as cinco classes de advérbios focalizadores aqui estudados:

${ }^{20}$ Para uma/um parecerista, a ordem também > inclusive é igualmente possível, como em seu exemplo (i):

(i) O João esqueceu também inclusive a festa de aniversário

Concordamos que (i) seja gramatical, desde que o escopo de também seja o verbo esqueceu e o escopo de inclusive seja o DP a festa de aniversário, o que naturalmente envolveria uma derivação em que o VP, contendo uma cópia de V, se moveria ao especificador do núcleo probing associado a também ("[ $\mathrm{V}_{\mathrm{VP}}$ esqueceu a festa de aniversário]"), com reconstrução do V no especificador deste núcleo atrator, seguido pela soldagem de também e movimento do remanescente "O João esqueceu" à esquerda de também. Posteriormente, antes da entrada de inclusive na derivação, novo núcleo probing a ele associado atrairia a festa de aniversário, a seu especificador, seguido pela soldagem de inclusive no especificador logo acima, e pelo movimento do remanescente "O João esqueceu também", derivando a ordem em (i).

A mesma derivação deve ser assumida para derivar (ii), também oferecida pela/o parecerista, que aparentemente seria um contra-exemplo à hierarquia que aqui se propõe a partir dos dados em (49-50). (ii) só é possível na leitura em que também tem escopo sobre $\mathrm{o} \mathrm{V}$ e particularmente sobre as bananas, o que não seria um problema à hierarquia que se está tentando propor.

(ii) O João prefere também particularmente as bananas 


\section{(51) A hierarquia dos AdvPs focalizadores}

de inclusão $>$ particularizadores $>$ aditivo não escalar $>$ aditivo escalar $>$ de exclusão

inclusive $>$ particularmente $>$ também $>$ até $>$ só

incluso $>$ particularmente $>$ también $>$ hasta $>$ solo

Determinamos, então, a posição relativa das cinco classes de advérbios focalizadores descritos anteriormente. Faz-se, agora, necessário tratar de determinar a posição que os advérbios de (51) ocupam em relação aos advérbios da hierarquia de Cinque.

\section{A posição dos advérbios focalizadores na hierarquia de Cinque}

Cinque (1999) já havia mostrado que advérbios habituais (solitamente "geralmente") precedem a negação pressuposicional (mica) que precede, por sua vez, più ('mais') (cf. (52)):

$$
\text { solitamente }>\text { mica }>\text { già }>\text { più ... (CINQUE, 1999, p. 6) }
$$

Segundo o raciocínio avançado em Tescari Neto (2015a: 582), se considerarmos por enquanto o advérbio só - o mais baixo entre os ditos focalizadores da hierarquia em (51) acima -, e os advérbios de (52), no que diz respeito às relações de transitividade na sequência linear das sentenças $((53 a, b)$ e $(54 a, b))$, de Tescari Neto (2015a: 582), teremos o quadro (parcial) em (54c):

(53) a. Non ha mica solo mangiato la pasta [Italiano]

Não Aux NEG só comer. PART a massa

'Ele/ela não comeu a massa não'

b. *Non ha solo mica mangiato la pasta (G. Cinque, com. pessoal)

(54) a. Lui ha solo completamente distrutto una cosa, la sua casa [Italiano]

Ele tinha só completamente destruído uma coisa, a sua casa 'Ele tinha só completamente destruído uma coisa: a sua casa'

b. *Lui ha completamente solo distrutto una cosa, la sua casa (G. Cinque, comunicação pessoal) 
c. solitamente/usually/geralmente > 'mica'> solo/only/só > già/ already/já ...

Dadas as relações de transitividade discutidas acima é válido perguntar onde só/solo/only (e os advérbios associados ao foco de (51) da seção anterior) se posicionam em relação aos demais advérbios da hierarquia de Cinque. As sentenças apresentadas até o momento e os dados em (55-56), a seguir, sugeririam que só se posiciona numa "zona de fronteira" em IP, mais precisamente numa posição intermediária entre AdvPs altos e AdvPs baixos da hierarquia em (52) (ver, para isso, (57)).

(55) TAnterior já/already/già:

A: - O que o José já limpou?

B: - Ele só já limpou a casaB': - *Ele já só limpou a casa

(56) Aspcontinuative ainda/still/ancora:'

a. *Ele ainda só não limpou a casa ${ }^{21}$

b.Ele só ainda não limpou a casa

(57) Solitamente/usually (AspHabitual) > mica (Negação pressuposicional)

$>$ solo/only (FocExclusive) > já/già/already (Tanterior) > ainda/ancora/ still (Aspcontinuative) (TESCARI NETO, 2015a: 582)

Seguindo o raciocínio de Tescari Neto (2015a: 583), se se aplicam testes de transitividade para só e os advérbios posicionados nas proximidades do aspecto habitual, pode-se determinar a posição de só junto aos demais advérbios da hierarquia de Cinque. Só se posiciona necessariamente abaixo de finalmente (o advérbio de aspecto tardio), de tendencialmente (advérbio de aspecto predisposicional) e de novamente (advérbio de aspecto repetitivo) (cf. (58a-c), respectivamente, de Tescari Neto (2015a: 583).

(58) a. *O José só finalmente perdeu a cabeça

a'. O José finalmente só perdeu a cabeça

b. *O José só tendencialmente perde a cabeça do nada

\footnotetext{
${ }^{21}$ Há falantes que aceitam (56a) desde que ainda receba acento de foco. Mas, nesse caso, (56a) claramente não formaria um par mínimo com (56b).
} 
b'. O José tendencialmente só perde a cabeça do nada

c. *O José só novamente perdeu a cabeça

c'. O José novamente só perdeu a cabeça

Não é possível, no entanto, estabelecer uma ordenação entre só e os advérbios frequentativo (58d, d'), volitivo (58e, e') e acelerativo $\left(58 f, f^{\prime}\right)$ :

(58) d. O José só frequentemente perde a cabeça (não raramente!)

d'. O José frequentemente só perde a cabeça

e. O José só voluntariamente fez a tarefa ${ }^{22}$

e'. O José voluntariamente só fez a tarefa

f. O José só rapidamente lava a louça

f'. O José rapidamente só lava a louça

g. O José só já lavou a louça

g'. */??O José já só lavou a louça (TESCARI NETO: 2015a: 583)

Essa ordenação livre, conforme apontamos em outro trabalho (TESCARI NETO, 2015a), na verdade é tão somente aparente. A assunção de uma versão da análise de Kayne (1998) nos leva a inferir que, após o movimento do constituinte sob o escopo de só, o outro advérbio pode ou não se se deslocar junto com o remanescente, o que cria a ilusão de não ser possível estabelecer uma ordem rígida entre os advérbios em questão. Ver as fig. 6, 7 e 8 a seguir, em que a fig. 6 corresponde ao que há de comum na história derivacional dessas sentenças; a figura 7 (mais adiante) corresponde aos passos finais da derivação de $(58 \mathrm{~d}, \mathrm{e}, \mathrm{f})$ e a fig. 8 , bem mais adiante ainda, à derivação de (58d',e',f'). Entretanto, o fato de só c-comandar já (58g,g') é uma importante evidência a favor da ideia de que só ocupa uma posição rígida e fixa na hierarquia: só segue novamente (58c,c').

Conforme sugere a figura 6 , um núcleo probing $\left(\mathrm{K}^{0}\right)$ atrai, para o seu especificador, o constituinte sob o escopo do advérbio frequentativo

\footnotetext{
${ }^{22}$ Para uma/um parecerista, (58e,f) são agramaticais, o que leva a duas possíveis hipóteses: (i) pode ser que ela/ele esteja considerando a posição 'baixa' de só (não discutida aqui, que, em PB, pode ser também realizada pelo advérbio exclusivamente cf. Tescari Neto (2015a)); ou (ii) que se esteja considerando a posição alta do advérbio acelerativo rapidamente.
} 
(ver, na figura em questão, o passo indicado como (1)).. Na sequência, o advérbio é Soldado no especificador logo acima, em consonância com a hierarquia de Cinque. A soldagem do advérbio é seguida pelo movimento do remanescente (ver o passo indicado como (2) na fig. 6). O movimento do remanescente restaura a ordem anterior, o que cria a impressão da ausência de movimentos. Esses passos derivacionais acima descritos - e indicados na figura 6 como (1) e (2) - são comuns à derivação das sentenças (58 d/d', e/e', f/f').

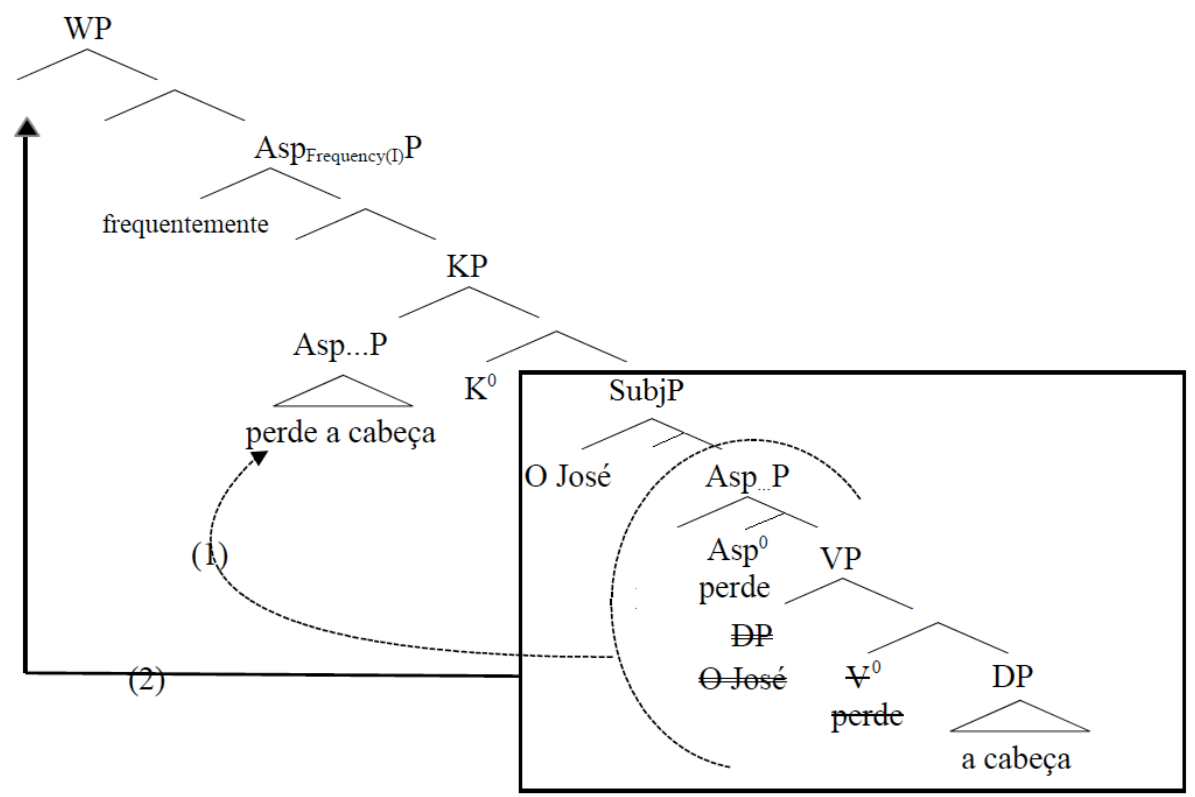

Figura 6 - A derivação de (58d, d'; e, e'; f, f'): primeiros passos ${ }^{23}$ Fonte: adaptado de Tescari Neto (2015a: 584)

A derivação das sentenças em que só precede o outro advérbio em (58d-g) tem história semelhante, conforme já apontado em Tescari Neto (2015a: 584): uma vez que o escopo de advérbios é atribuído, na Sintaxe

\footnotetext{
${ }^{23} \mathrm{Na}$ representação mostrada na fig. 6, a projeção Asp...P indica as várias projeções aspectuais da hierarquia de Cinque c-comandadas pelo aspecto frequentativo (AspFrequency(I)P) que por sua vez c-comandam o VP. Pela fig. percebe-se que aqui se assume uma posição criterial para o Sujeito, SubjP, no espírito de Rizzi (2004).
} 
visível, por meio de movimento (KAYNE, 1998; MUNARO, 2011; TESCARI NETO, 2013), antes da Soldagem de só, um núcleo atrairia o constituinte que porta o traço de foco a seu especificador. Esse constituinte conteria inclusive o advérbio frequentemente/voluntariamente/ rapidamente. Na sequência só seria soldado no especificador acima e o remanescente seria movido ao especificador acima de só, restaurando, outra vez, a ordem anterior à Soldagem dos advérbios em questão.

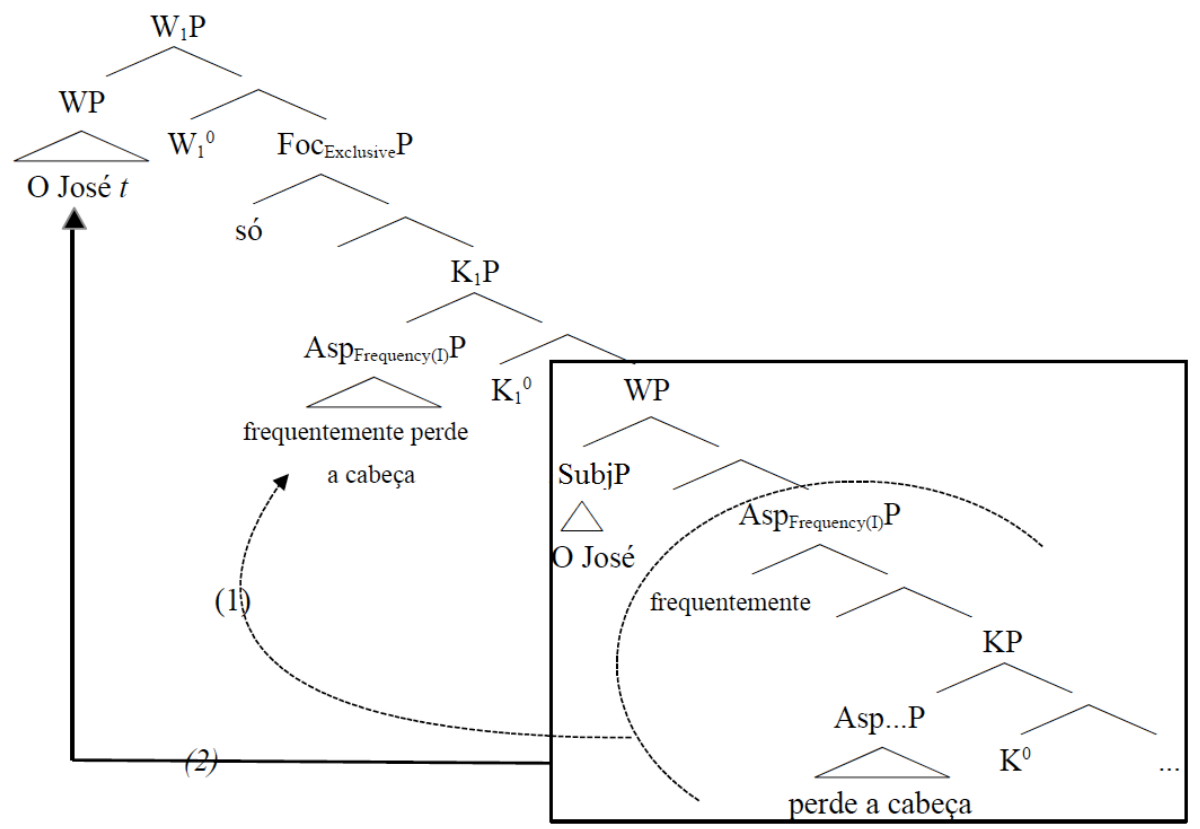

Figura 7 - A ordem só - AdvP

Fonte: adaptado de Tescari Neto (2015a: 585)

Se frequentemente/voluntariamente/rapidamente precede só (como em (58d', e', f')), temos, inicialmente, conforme apontado também em Tescari Neto (2015a), a mesma história derivacional descrita nas figuras 6 e 7. As derivações de (58d,e,f) se diferenciarão das de (58d',e',f') no que diz respeito ao constituinte alçado ao especificador do núcleo probing e no que diz respeito ao material alçado como remanescente: o constituinte que se move ao Spec do núcleo probing não conterá frequentemente/voluntariamente/rapidamente, que se moverá como 
parte do remanescente. Esse movimento do remanescente cria, como já se disse, a impressão de não ser possível estabelecer uma ordenação rígida e fixa entre só e frequentemente/voluntariamente/rapidamente.

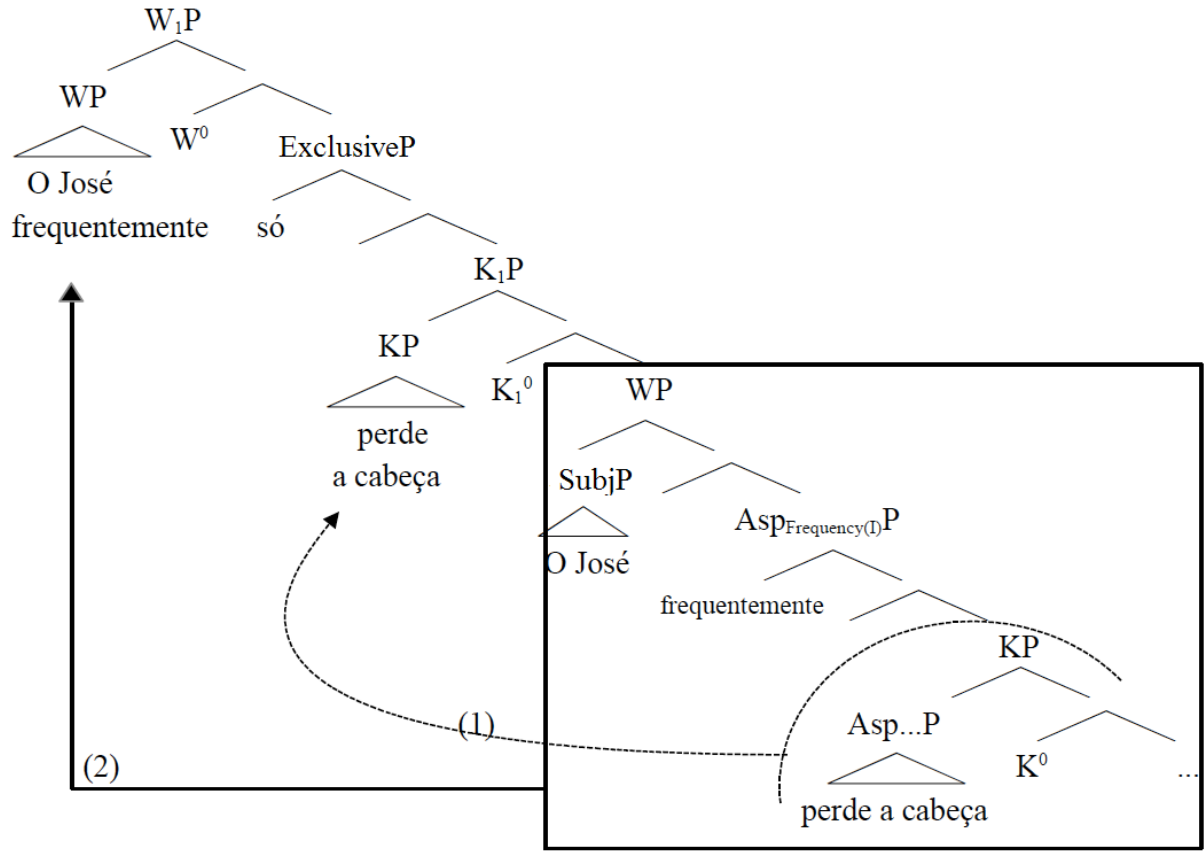

Figura 8 - A derivação da ordem $\mathrm{AdvP}$ - AdvP focalizador exclusivo Fonte: adaptado de Tescari Neto (2015a: 586)

A conclusão que se tira dos dados até então discutidos é que só se posiciona entre as projeções do Asprepetitive(I) (de novo/again) e do AspFrequentative(I) (frequentemente), conforme (59), sendo, portanto, um AdvP “alto". Se só, como vimos na seção anterior, é o advérbio focalizador mais baixo entre os advérbios focalizadores (conforme (51)), conclui-se que os advérbios ditos focalizadores se posicionam entre os advérbios altos. Resta somente determinar como os advérbios focalizadores se distribuem na sequência de AdvPs ditos altos da hierarquia de Cinque: posicionam-se um atrás do outro, todos de uma vez, num ponto específico da hierarquia ou cada advérbio associado a foco se posiciona num ponto da hierarquia entre dois outros advérbios de Cinque? 
[francamente MoodSpeechAct $>$ [felizmente MoodEvaluative $>$ [supostamente MoodEvidential $>[$ provavelmente ModEpistemic $>[$ uma vez TPast $>[$ então TFuture $>$ [talvez Moodirrealis $>$ [necessariamente ModNecessity [possivelmente ModPossibility $>$ [geralmente AspHabitual $>$ [finalmente AspTardive $>$ [tendencialmente AspPredispositional $>$ [de novo AspRepetitive $(\mathrm{I})>\left[\right.$ só Exclusive $>{ }^{24}$ [frequentemente AspFrequentative $(\mathrm{I})>[$ de gosto Modvolitive $>[$ rapidamente Aspcelerative $(\mathrm{I})>[j a ́$ TAnterior $>\left[\right.$ não mais Asp $_{\mathrm{T}}$ erminative $>\ldots$

(adaptado de TESCARI NETO, 2015a: 587)

Os focalizadores de (51) da seção anterior se ordenam rigidamente também em relação aos demais AdvPs da hierarquia de Cinque (1999). Como se viu nesta seção, só aparece entre o advérbio alto novamente (Asprepetitive(I)) e o advérbio frequentemente (AspFrequentative(I)), colocando-se numa zona fronteiriça no Middlefield, entre os advérbios altos e os baixos.

Uma vez que as outras quatro classes de AdvPs focalizadores de (51) ocupam posições mais altas do que só, é de se esperar que também se ordenem acima de frequentemente (AspFrequentative(I)). (60-61) confirmam esta previsão.

(60) a. O João inclusive frequentemente esquece a data de aniversário da esposa

b. *O João frequentemente inclusive esquece a data de aniversário da esposa

(61) a. O João particularmente frequentemente esquece a data de aniversário da esposa

${ }^{24}$ Uma/um parecerista, a propósito de (59), indagou: "É estranho que projeções de AspP sejam interrompidas por projeções de conteúdo informacional como Foc". Na verdade, a projeção do advérbio de exclusão só, assim como as posições dos advérbios em negrito na hierarquia em (68), mais adiante, são apenas posições de Soldagem para advérbios que se associam ao XP que virá a ser o foco da sentença. Os movimentos que aqui são assumidos ao especificador do núcleo atrator garantem, no espírito de Kayne (1998) revisitado, apenas atribuição de escopo, que, para Kayne, crucialmente se dá na sintaxe visível. Haverá ulterior movimento do foco associado ao advérbio, para o FocP da periferia esquerda. A esse respeito, ver Quarezemin e Tescari Neto (2015). 
b. *O João frequentemente particularmente esquece a data de aniversário

Estando inclusive e particularmente acima de frequentemente, de acordo com os dados em (60-61), e estando inclusive e particularmente acima de também, até e só, conforme se mostrou na seção anterior (cf. (51)), por transitividade conclui-se que também e até também se posicionam acima de frequentemente, ainda que seja difícil determinar a posição relativa dos dois primeiros em relação a frequentemente, provavelmente pelas mesmas razões que tornavam difícil o trabalho de determinar a posição de só em relação a alguns advérbios baixos, como se disse acima ao discutir as ocorrências em (58). O movimento do remanescente contendo frequentemente em $(62 \mathrm{~b}, 63 \mathrm{~b})$ deveria ser a razão para o porquê de essas sentenças, apesar de (aparentemente) violarem a ordem hierárquica, serem gramaticais. Naturalmente, estudos futuros deverão explicar por que apenas a alguns advérbios é facultada a possibilidade de se moverem junto com o material remanescente, sem darem lugar a agramaticalidades.

(62) a. O João também frequentemente esquece a data de aniversário da esposa

b. ?'O João frequentemente também esquece a data de aniversário da esposa)

(63) a. O João até frequentemente esquece a data de aniversário da esposa

b. O João frequentemente até esquece a data de aniversário da esposa)

Que os advérbios de (51) se posicionem abaixo de novamente (Asprepetitive( $\mathrm{I}_{\text {) }}$ ), o mais baixo advérbio dentre os advérbios altos da hierarquia de Cinque, pode ser visto em (64-67).

(64) a. O João novamente inclusive esqueceu a data de aniversário... b. */?O João inclusive novamente esqueceu a data de aniversário...

(65) a. O João novamente particularmente esqueceu a data de aniversário... 
b. *O João particularmente novmente esqueceu a data de aniversário...

(66) a. O João novamente também esqueceu a data de aniversário...

b. *O João também novamente esqueceu a data de aniversário...

(67) a. O João novamente até esqueceu a data de aniversário...

b. *O João até novamente esqueceu a data de aniversário...

A combinação de (51-59) com (60-67), tendo em vista os testes de transitividade - tão caros à metodologia do programa Cartográfico -, nos leva a concluir que as cinco classes de advérbios focalizadores se ordenam rigidamente também em relação aos advérbios da hierarquia de Cinque. A zona do Middlefield ocupada por advérbios focalizadores é exatamente aquela entre o advérbio alto novamente (Asprepetitive(I)) e o advérbio frequentemente (AspFrequentative(I)). (68) corresponderia a um estrato de uma versão reformulada da hierarquia universal de Cinque (1999), apresentada em (5), que passa agora a contemplar também as cinco classes dos advérbios ditos focalizadores:

(68) Estrato da Hierarquia Universal de Cinque completada com os AdvPs focalizadores:

[geralmente AspHabitual $>[$ finalmente AspTardive $>$ [tendencialmente Asp Predispositional $>[$ de novo Asprepetitive $(\mathrm{I})>[$ inclusive Inclusion $>$ [particularmente Particularizer $>$ [também Non-scalar additive $>$ [até Scalar additive $>[$ só Exclusive $>[$ frequentemente AspFrequentative $(\mathrm{I})>[$ de gosto Modvolitive $>[$ rapidamente AspCelerative(I) $>[$ já TAnterior $>\ldots$

Como se vê, os advérbios ditos focalizadores ocupam uma posição intermediária no Middlefield, i.e., se posicionam entre os advérbios altos ou sentenciais - cujo representante mais baixo é o advérbio novamente (I) - e os advérbios baixos, cujo representante mais alto é o advérbio frequentemente (I).

\section{Considerações finais}

O objetivo deste trabalho foi determinar as posições que os advérbios tradicionalmente denominados de focalizadores ocupam na 
estrutura da oração, i.e., a posição que ocupam na hierarquia de Cinque (1999). Tomando como ponto de partida o princípio do "One Feature, One Head", de Kayne (2005), a hipótese inicial era a de que para cada classe semântica distinta de advérbio associado ao foco deveria corresponder uma posição rígida e fixa na estrutura.

Para determinar essas posições dos advérbios ditos focalizadores, apresentamos muito sucintamente uma descrição de cada uma das cinco classes desses AdvPs. Na sequência, apresentamos a metodologia de pesquisa em Cartografia, com especial destaque às relações de transitividade: se um dado constituinte A deve preceder um constituinte B da mesma categoria, sendo agramatical a ordem inversa (i.e., BA), isso significa que, na hierarquia ou estrutura de base, A precede B.

Determinamos a posição que cada uma das cinco classes de advérbios associados ao foco ocupa na estrutura da oração, e a posição desses advérbios em relação aos advérbios da hierarquia universal. Vimos que os focalizadores se posicionam entre novamente (Asprepetitivel) - o mais baixo advérbio entre os advérbios altos de Cinque (1999) - e frequentemente (AspFrequentativeI) - o mais alto entre os advérbios ditos baixos.

Naturalmente, uma vez que os advérbios, no quadro teórico de Cinque, são a lexicalização das distinções funcionais da oração no formato sintagmático e por isso mesmo ocupam a posição de Spec dos núcleos funcionais correspondentes, pesquisas futuras deverão encontrar, no formato nuclear, evidências para essas cinco classes de advérbios associados ao foco, também rigidamente ordenadas.

\section{Agradecimentos}

Agradecimentos a um dos pareceristas desta revista que, com sua leitura atenciosa e suas observações precisas, gentilmente contribuiu para que o texto ganhasse em qualidade. Agradecimentos também a Sonia Cyrino, pela supervisão de meu estágio de pós doutorado realizado na UNICAMP e pela discussão dos dados aqui problematizados; à FAPESP, pelo apoio financeiro (processo 2013/040011); e às audiências do $25^{\text {th }}$ Colloquium on Generative Grammar (IKER, Bayonne, maio de 2015), do $6^{\text {th }}$ International Conference on Formal Linguistics (Tsinghua University, Pequim, novembro de 2014), do Encontro Intermediário do GT em Teoria da Gramática (Faculdade de Letras, UFMG, jul. de 2015) e das universidades de Veneza (outubro de 2013) e Campinas (março de 2014), onde versões preliminares deste trabalho foram apresentadas. 
Agradecimento especial à equipe editorial da RELIN, pelo eficiente trabalho na edição da versão final. Desnecessário dizer que possíveis inconsistências e erros que insistiram em permanecer são meus.

\section{Referências}

ADORNO, C. Focalizzatori fra connessione e messa a fuoco: il punto di vista delle varietà di apprendimento. Milano: Angeli, 2000.

AMBAR, M.On some specialadverbs, word order, and CP: variation vs. microvariation. Canadian Journal of Linguistics/Revue Canadienne de Linguistique, v. 53, n. 2/3, p. 143-179, 2008.

BAYER, J. Directionality and logical form: on the scope of focussing particles and Wh-in situ. Dordrecht: Kluwer Academic Publishers, 1996. http://dx.doi.org/10.1007/978-94-017-1272-9

BENINCÀ, P.; MUNARO, N. Introduction. In: (Eds.). Mapping the left periphery: the cartography of syntactic structures - Vol. 5. New York: Oxford University Press, 2011.

CESARE, A.-M. de. On the Focusing Function of Focusing Adverbs: A Discussion Based on Italian Data. Linguistik online, v. 44, n. 4, 2010. Disponível em: $<$ http://www.linguistik-online.de/44_10/decesare.html $\geq$. Acesso em: 5 jul. 2015.

CHOMSKY, N. Deep structure, surface structure, and semantic interpretation. In: STEINBERG, D. et al. (Eds.). Semantics: An interdisciplinary reader in philosophy, linguistics and psychology. Cambridge: Cambridge University Press, 1971. p. 62-119.

. Barriers. Cambridge, Massachusetts: MIT Press, 1986.

Press, 1995.

. The Minimalist Program. Cambridge, Massachusetts: MIT

CINQUE, G. Adverbs and functional heads: a cross-linguistic perspective. New York: Oxford University Press, 1999.

. Mapping Functional Structure: a Project. In: .Functional

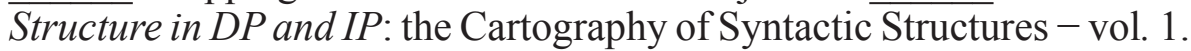
Oxford: Oxford University Press, 2002. p. 3-11.

. Restructuring and functional heads: the cartography of syntactic structure - vol. 4. New York, Oxford: Oxford University Press, 2006. 
CINQUE, G.; RIZZI, L. The cartography of syntactic structures. In: HEINE, B.; NARROG, H. (Eds.). The Oxford Handbook of Linguistic Analysis. New York: Oxford University Press, 2010. p. 51-65.

CYRINO, S. M. L. On richness of tense and verb movement in brazilian portuguese. In: CAMACHO-TABOADA, V. et al. (Eds.). Information structure and agreement. Amsterdam: John Benjamins, 2013. p. 297-318. http://dx.doi.org/10.1075/la.197.11cyr

DONATI, C. La Sintassi: regole e strutture. Bologna: Il Mulino, 2008.

FERRARI, L.; GIAMMATTEO, M.; ALBANO, H. Operadores de foco: el caso de incluso, hasta, solo y aun. Cuadernos de la Alfal, v. 3, p. 30-41, 2011. Disponível em: <http://mundoalfal.org/sites/default/files/ revista/03_cuaderno_005.pdf $>$. Acesso em: 5 jul. 2015.

JACKENDOFF, R. Semantic interpretation in Generative Grammar. Cambridge: MIT Press, 1972.

KAYNE, R.S. Overt vs. covert movements. Syntax, v. 1, p. 128-191, 1998. http://dx.doi.org/10.1111/1467-9612.00006

. Movement and Silence. New York: Oxford University Press, 2005.

KRIFKA, M. Basic notions of information structure. In: FÉRY, C. et al. (Eds.). Working papers of the interdisciplinary studies on information structure (ISIS): vol. 6. Potsdam: Universitätsverlag Potsdam, 2007.

LIMA, R. B. Advérbios focalizadores no português brasileiro. 2006. 130f. Dissertação (Mestrado em Linguística) - Universidade Federal de Alagoas, Maceió, 2006.

LONGOBARDI, G. In defense of the correspondence hypothesis: island effects and parasitic constructions in LF. In: HUANG, C.-T. J.; MAY, R. (Eds.). Logical structure and Linguistic Structure. Dordrecht: Kluwer, 1992. p. 149-196.

http://dx.doi.org/10.1007/978-94-011-3472-9_6

MUNARO, N. On the syntax of focalizers in some Italo-romance dialects. In: BAAUW, F. et al. Romance Languages and Linguistic Theory. Amsterdam: John Benjamins, 2011. p.157-174.

POLLOCK, J.-Y. Verb Movement, universal grammar, and the structure of IP. Linguistic Inquiry, v. 20, n. 3, p. 365-474, 1989. 
QUAREZEMIN, S.; TESCARI NETO, A. Da sintatização dos focos contrastivo e exaustivo em CP e das estratégias de marcação de foco. ReVEL, edição especial, n. 10, p. 42-77, 2015. Disponível: <http://www. revel.inf.br/files/eb575603b243ddb4990470247c2ece43.pdf $\geq$. Acesso em: 30 jan. 2016.

QUIRK, C. R. et al. A grammar of the contemporary English. London: Longman, 1976.

RICCA, D. Osservazioni preliminary sui focalizzatori in italiano. In: DITTMAR, N.; RAMAT, G. (Orgs.). Grammatik und Diskurs: Studien zum Erwerb des Deutschen und des Italienischen/Grammatica e discorso: Studi sull'acquisizione dell'italiano e del tedesco. Tübingen: Stauffenburg, 1999.

RIZZI, L. On the form of chains: criterial positions and ECP Effects. 2004. Disponível em: <http://www.ciscl.unisi.it/doc/doc_pub/Rizzi_2004On_the_form_of_chains.pdf $>$. Acesso em: 30 abr. 2016.

SANTANA, M.S. A sintaxe dos advérbios em português. Dissertação (Mestrado em Linguística) - UFRJ, Rio de Janeiro, 2005.

SHU, C. Sentence Adverbs in the Kingdom of Agree. 2011. $263 \mathrm{f}$. Dissertação (Doutorado em Filosofia) - Stony Brook University, New York, United States of America, 2011.

TESCARI NETO, A. On Verb Movement in Brazilian Portuguese: a cartographic study. Tese (Doutorado em Ciências da Linguagem) Università Ca' Foscari di Venezia, Italia, 2013. Disponível em: $<$ http:// arca.unive.it/handle/10278/2957 . Acesso em: 6 jul. 2015.

. 'Só', 'exclusivamente' e suas posições na sentença. Alfa (UNESP), São Paulo, v. 59, n. 3, p. 573-602, 2015a. Disponível em: <http://seer.fclar. unesp.br/alfa/article/view/6419>. Acesso em: 30 jan. 2016.

. Por que advérbios altos não são diagnósticos para o movimento do verbo? Linguística, v. 31, n. 2., p. 27-46, 2015b. Disponível em: $<$ http://www.scielo.edu.uy/pdf/ling/v31n2/v31n2a03.pdf $>$. Acesso em: 30 jan. 2016.

ZUBIZARRETA, M. L. Prosody, focus and word order. Massachusetts: MIT Press, 1998.

ZYMAN, E. Two investigations of adverbs and clause structure in English. Senior Thesis. Princeton University, 2012. 